Canadian Journal of Fisheries and Aquatic Sciences

Canadian

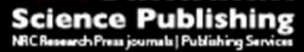

Journal canadien des sciences halieutiques et aquatiques

\title{
Classification of Otoliths of Fishes Common in the Santa Barbara Basin Based on Morphology and Chemical Composition
}

\begin{tabular}{|r|l|}
\hline Journal: & Canadian Journal of Fisheries and Aquatic Sciences \\
\hline Manuscript ID & cjfas-2015-0566.R2 \\
\hline Manuscript Type: & Article \\
\hline Date Submitted by the Author: & $19-$ Sep-2016 \\
\hline Complete List of Authors: & $\begin{array}{l}\text { Jones, William; University of California, San Diego, Scripps Institution of } \\
\text { Oceanography } \\
\text { Checkley, David M., Jr.; University of California - San Diego }\end{array}$ \\
\hline Keyword: & $\begin{array}{l}\text { OTOLITHS < General, Discriminant function analysis, Random forest } \\
\text { analysis, California Current, Elliptic Fourier }\end{array}$ \\
\hline
\end{tabular}

\section{SCHOLARONE \\ Manuscripts}


Classification of Otoliths of Fishes Common in the Santa Barbara Basin Based on

2 Morphology and Chemical Composition

4 William A. Jones a , w3jones@ucsd.edu, 231-519-3974, corresponding author

6 David M. Checkley, Jr. ${ }^{\text {a }}$, dcheckley@ucsd.edu

$8{ }^{\text {a }}$ Scripps Institution of Oceanography, University of California, San Diego, CA 920930218

10

12 
Otolith Classification

\section{ABSTRACT \\ 14 \\ Morphological and chemical features of fish otoliths are used to}

16 distinguish between populations and stocks. We hypothesized that these features can also be used to distinguish between fishes of different

18 taxonomic groups common in and near the Santa Barbara Basin, including mesopelagic, pelagic and demersal fish. Sagittal otoliths obtained from 905

20 fish representing 6 taxonomic groups were imaged and 12 geometric and 59 elliptic Fourier morphometric features were extracted. A subset of 143

22 otoliths was also analyzed for $\mathrm{Li}, \mathrm{Na}, \mathrm{Mg}, \mathrm{K}, \mathrm{Mn}, \mathrm{Sr}$, and $\mathrm{Ba}$. We used chemical composition in addition to morphology because the latter may be

24 altered between otolith formation and analysis. Two sets of classifiers were made, one using only morphometric features and one using both

26 morphometric and element features. Random forest analysis was generally superior to discriminant function analysis. Highest classification success,

28 evaluated using cross-validation and otoliths of masked identity, was achieved with multiple feature types. The ten strongest discriminatory

30 features of all available feature types were used in the final classification models. Our method is applicable to the classification of otoliths recovered

32 from guts, feces, middens and sediments as well to classify other biological objects. 


\section{Otolith Classification}

\section{KEY WORDS}

36 Otolith - Elliptic Fourier - Discriminant function - Random forest - ICP-MS - Trace elements - California Current - Shape - Mesopelagic

38 
Otolith Classification

\section{INTRODUCTION}

Otoliths are aragonite and protein structures in the inner ears of teleost fish that

42 function in hearing and balance (Popper et al. 2005). Otoliths are relatively resistant to alteration compared to other hard parts of fish and are often found in the guts and feces of

44 fish and in middens and marine sediments (Pierce et al. 1991; Nolf 1995). Methods are needed to taxonomically classify otoliths from these sources for use in food web analysis

46 and to construct chronologies of past abundances of fishes. Modern fish otoliths have morphological and chemical features that vary between species and with physiology,

48 ontogeny, diet and the environment (Campana and Casselman 1993; Campana 1999; Elsdon and Gillanders 2003). These features can be used to discriminate between otoliths

50 of fish that differ in these characteristics (Campana and Casselman 1993; Campana et al. 2000; Disspain et al. 2015). We develop, test and compare models to classify otoliths

52 from groups of species of modern fish based on otolith shape and elemental composition.

We hypothesized that features from modern otoliths can be used to discriminate

54 between taxa common in and near the Santa Barbara Basin (SBB). We use three types of features: geometric shape (Tuset et al. 2003), elliptic Fourier descriptors (Kuhl and

56 Giardina 1982), and elemental composition (Campana 1999). Elemental composition was included because the morphology of an otolith may be altered between its formation and

58 analysis whereas elemental composition is stable (Degens 1969).

The motivation for our study is to develop a method to identify otoliths found in

60 sediment cores. Fish scales have been most commonly used to create a chronology of past fish abundance in waters overlying anoxic basins (Soutar and Isaacs 1969; Field et

62 al. 2009; Skrivanek and Hendy 2015). However, scale production varies greatly between fish species, whereas all fish have a constant number of otoliths (Field et al. 2009). The

64 present study contributes to our ability to assign otoliths extracted from anoxic sediments to taxonomic groups.

66 We focus on three objectives that contribute to methods of otolith classification.

First, we use multiple types of features to taxonomically classify otoliths. Second, we

68 compare discriminant function analysis and random forest analysis for otolith classification. Third, we use otoliths from mesopelagic as well as pelagic and demersal 
Otolith Classification

70 fishes to ensure inclusion of all types of fish that might occur in deep water sediments.

\section{MATERIALS AND METHODS}

A flow chart shows the processes from otolith acquisition to classification (Figure 1). All otoliths were from known species and acquired from either live-caught fish or

76 museum collections. Each otolith was imaged and morphometric features were extracted. A subset of otoliths analyzed for morphometric features was also analyzed for element

78 concentration. Following feature extraction, two classification models were developed: one used only morphometric features and a second used both morphometric and

80 elemental features.

\section{Otolith Sources}

Otoliths were obtained from recently captured fish and museum collections of

84 known species. Fish were captured by net and hook-and-line at multiple locations, stored frozen $\left(-4^{\circ} \mathrm{C}\right)$ and thawed immediately before use. Standard length (SL) and wet weight

86 were, for the majority of fish, measured and recorded before otolith removal. Both sagittal otoliths (sagittae), the largest of three otolith pairs, were extracted with forceps

88 and a dissecting microscope, rinsed in 18 Milli Q water (i.e., quartz-distilled water with resistivity $>18.1 \mathrm{M} \Omega$ ), excess biological and/or membranous material removed, air dried

90 and stored in vials.

In addition, otoliths from the Fitch Otolith Collection at the Natural History

92 Museum of Los Angeles County (LACM) and the Scripps Institution of Oceanography Otolith Collection were obtained. Otoliths from these collections were used for

94 morphometric analysis only and returned.

\section{Image Acquisition}

All otoliths were imaged using Zeiss compound and Wild dissecting light

98 microscopes, each with a trinocular head and Spot 5.0 megapixel camera. An image of one otolith, either right or left, was randomly selected for each fish, from which

100 morphometric features were extracted. Morphology does not differ between left and right 
Otolith Classification

otoliths (Zhang et al. 2014). Individual otoliths were imaged when dry and on a glass

102 slide and illuminated by reflected light using a black background. Media Cybernetics Image-Pro Plus 7.0 software was used to acquire and save images as JPEG files. The

104 magnification of each image was recorded. For each magnification, mm/pixel was estimated using a stage micrometer.

\section{Image Processing}

108 MATLAB's Image Processing and Statistics toolboxes were used (MATLAB Release 2014b, The MathWorks, Inc.). A series of pre-processing steps were used on

110 each original JPEG image prior to feature extraction. First, the color JPEG image was converted to gray scale using the 'rgb2gray' function. Second, a threshold was used to

112 create a binary image with the otolith white and the background black. Pixels with gray scale intensity above a threshold of 18 (out of 255) represented the white otolith and

114 those at or below 18 represented the black background. This threshold value worked well for most images but, in some cases, a lower threshold value was used. Next, the 'imfill'

116 function (cf., morphological closing) was used to fill any false black regions within the otolith object and the 'bwareaopen' function (cf., morphological opening) was used to fill

118 any false white regions within the black background.

\section{Geometric Features}

The 'regionprops' function in MATLAB was used to extract nine geometric

122 (GEO) features from the otolith in the binarized image: area $(A)$, perimeter $(P)$, major axis length $(M A L)$, minor axis length $(m A L)$, equivalent diameter $(E q D)$, extent $(E x t)$,

124 eccentricity $(E c c)$, convex area $(C n v A)$, and solidity $(S o l)$. Three additional features were derived from the extracted features: roundness $(R n d, 4 \pi A /(2 P))$, aspect ratio $(A s p R$,

$126 M A L / m A L)$, and ellipticity $(E l l,(M A L-m A L) /(M A L+m A L))$. Features are defined at http://www.mathworks.com/help/images/ref/regionprops.html and in Table S3. The

128 geometric features were then converted from pixels to $\mathrm{mm}$ or square pixels to $\mathrm{mm}^{2}$.

\section{Elliptic Fourier Features}

An elliptic Fourier series was estimated to mathematically represent the shape of 
Otolith Classification

132 the edge of the binary image of each otolith, resulting in a series of normalized elliptic Fourier (EF) features for each otolith (Kuhl and Giardina 1982). EF features have been

134 used to classify a wide variety of biological objects, including grains, shells, plant foliage, and human mandibles (e.g., Innes and Bates 1999; Mebatsion et al. 2012).

136 First, a series of $x$ and $y$ coordinates were measured along the closed-contour (edge) of the otolith image at predetermined pixel intervals. One pixel in the otolith

138 image was selected as a reference starting point. 100 evenly spaced pixels on the otolith boundary were then selected, moving clockwise around the otolith. The entire perimeter

140 of the otolith was thus described by the 100 coordinates.

Second, this set of 100 coordinates was expressed as a chain code, each link

142 representing one step and indicating the direction moved from one coordinate to the next. Chain coding was completed when the reference point was reached 100 samples later.

144 Finally, a Fourier series expansion was performed, which decomposes the chain code into series of harmonics (Kuhl and Giardina 1982). Each harmonic is described by

146 four EF descriptors $\left(a_{\mathrm{n}}, b_{\mathrm{n}}, c_{\mathrm{n}}, d_{\mathrm{n}}\right.$, where $\mathrm{n}=$ harmonic number and $a, b, c$ and $d$ are Fourier coefficients: $a$ (cosine) and $b$ (sine) in the $x$ dimension and $c$ (cosine) and $d$ (sine)

148 in the $y$ dimension). The first harmonic $(n=1)$ is related to the overall size of the otolith and the following harmonics provide increasingly detailed information about the

150 complexity of the otolith's shape. Thirty harmonics were used, capturing greater than 99.99\% of the mean cumulated Fourier power (Mérigot et al. 2007; Stransky et al. 2008)

152 and resulting in $120 \mathrm{EF}$ descriptors for each otolith. The EF descriptors were normalized to be invariant with respect to otolith size, orientation, and chain code starting point by

154 fixing $a_{1}=1$ and $b_{1}=c_{1}=0$ (Kuhl and Giardina 1982). The cosine and sine terms of each harmonic for $x\left(a_{\mathrm{n}}, b_{\mathrm{n}},\right)$ and $y\left(c_{\mathrm{n}}, d_{\mathrm{n}}\right)$ were combined using EF $x_{\mathrm{n}}=\left[a_{\mathrm{n}}+b_{\mathrm{n}}\right]^{2}$ and EF $y_{\mathrm{n}}=$

$156\left[c_{\mathrm{n}}+d_{\mathrm{n}}\right]^{2}$, resulting in 60 total EF features, 59 of which were unique and used in further analyses. Combining the cosine and sine components reduces the number of overall

158 features while retaining information on the relative importance of each harmonic in quantifying an otolith's shape.

160

\section{Otolith Elemental Composition}


Otolith Classification

162 Trace elements in otoliths were measured using a Thermo Finnigan Element2 single collector inductively coupled plasma mass spectrometer (ICP-MS). Solution-based

164 ICP-MS of entire otoliths was used in order to integrate over the entire life history of each fish (Gillanders and Kingsford 2003). The elements ${ }^{7} \mathrm{Li},{ }^{23} \mathrm{Na},{ }^{25} \mathrm{Mg},{ }^{39} \mathrm{~K},{ }^{55} \mathrm{Mn},{ }^{88} \mathrm{Sr}$,

166 and ${ }^{138} \mathrm{Ba}$ were measured and expressed as ratios with respect to measured ${ }^{48} \mathrm{Ca}$ (Bath et al. 2000). Otoliths used in the element analysis were only from live-caught fish; museum

168 specimens could not be destroyed. When possible, otoliths for element analysis came from sampling events with at least six fish of the same species, providing sufficient

170 replicates to test for the effects of year and sample location on elemental composition. One sagittal otolith from a fish was randomly selected. The elemental composition of left

172 and right sagittae has been shown to not differ significantly in fish with bilateral symmetry (Rooker et al. 2001). Otoliths were cleaned in a Class 100 laminar flow hood

174 located within a Class 100 clean room. All polypropylene plasticware that came into contact with the otoliths for element analysis was acid washed for $24 \mathrm{~h}$ in heated $10 \%$

$176 \mathrm{HNO}_{3}$, rinsed three times in ultra-pure water, air-dried in a Class 100 laminar flow cabinet, and stored in zip-lock bags before use. To remove any remaining organic tissue

178 and/or contaminants, otoliths were transferred to acid-washed $0.6 \mathrm{~mL}$ polypropylene vials and rinsed for 5 minutes with $15 \%$ ultrapure $\mathrm{H}_{2} \mathrm{O}_{2}$ buffered with $0.05 \mathrm{~mol} \mathrm{~L}^{-1} \mathrm{NaOH}$.

180 Otoliths were then rinsed three times with Milli-Q water and air-dried overnight.

Cleaned otoliths were weighed and dissolved in a known volume of concentrated

182 Seastar ultrapure nitric acid $\left(\mathrm{HNO}_{3}\right)$ then diluted with Milli-Q water to make a 5\% nitric acid solution. Otolith identity was masked during analysis. Otoliths were analyzed in

184 random order and in groups of approximately ten. Instrument blanks $\left(5 \% \mathrm{HNO}_{3}\right)$ and standards were analyzed at the start of each group. Measured intensity was corrected

186 using a blank value for each sample estimated by linear interpolation between blanks measured before and after a series of samples. Instrument bias was corrected for by

188 measuring values of certified JPR (NIES/WAMRL Red Emperor, Lutjanus sebae) and NIST (Standard Reference Material, 1948, fish otoliths) reference material.

\section{Statistical Analyses}

192 Data consisted of 12 GEO, 59 EF and 7 ELM features (Tables S1, S2). Data were 
assessed for normality and homogeneity of variance using Kolmogorov-Smirnov and

194 Levene's tests, respectively (Lilliefors et al. 1967; Brown and Forsythe 1974). All data were log-transformed prior to further analyses. Bar graphs displaying the mean and

196 standard error for each GEO and ELM feature were used to visualize the differences and distributions of otolith features across taxonomic groups. The mean and standard error of

198 the EF features were plotted in relation to harmonic number for each taxonomic group. Single-factor analysis of variance (ANOVA) and the non-parametric Kruskal-Wallis test

200 were used to assess if each otolith feature differed between taxonomic groups. Features for which there was no significant variation between taxonomic groups were excluded

202 from the classification analysis. The Tukey HSD test was used to perform post hoc comparisons to ascertain which taxonomic groups differed from one another. Sampling

204 location (latitude), otolith size, and date (year) were also examined, using one-way and multi-factor ANOVA, as potential sources of variation between otolith features. The level

206 of significance for all tests was 0.05 , unless otherwise indicated.

We evaluated the ability of two methods to classify otoliths of known taxonomic

208 group whose identity was masked. First, we employed linear discriminant function analysis (DFA) in which class assignment occurs by sequentially bisecting the data with

210 linear discriminant functions derived from the independent variables (Williams 1983). Second, we used random forest analysis (RFA), a nonlinear ensemble or forest of many

212 tree classifiers in which class assignment occurs using an average of the forest of trees (Breiman 2001). We explored DFA and RFA classification models with various

214 combinations of input features and selected the best performing models. We evaluated model performance using a reduced number of input features using a DFA forward

216 stepwise procedure. Each stepwise procedure was performed 100 times to select a unique combination of input features for inclusion into the model, typically 5-12 features total.

218 Each feature was ranked according the number of times out of 100 it was included in the DFA stepwise model. A similar procedure was performed with the RFA, also resulting in

220 5-12 features for each of 100 analyses, which were then ranked by their frequency of occurrence.

222 To evaluate classification accuracy and to aid in model selection, each model was evaluated using 10-fold cross-validation (Kohavi 1995). One round of cross-validation 
Otolith Classification

224 involved random partitioning of the data into two complementary datasets: a "known" dataset, with $90 \%$ of the original data, used to train the model ("training dataset"), and an

226 "unknown" dataset, with the remaining $10 \%$ of the original data, used to test the model ("test dataset"). Ten rounds of cross-validation were performed and the results were

228 averaged. The misclassification error is defined as the average percent of errors made in classifying the test datasets in the 10 rounds. The 10 -fold cross-validation procedure was

230 performed 100 times and the misclassification error mean and standard deviation were calculated.

232 Canonical discriminant analysis (CDA) was used to separate the taxonomic groups in multidimensional space associated with the features used in the DFA and RFA

234 classifiers. Features from the best performing DFA and RFA models were used in the CDA and the first two canonical variables used as axes to plot the otolith data by

236 taxonomic group.

238 RESULTS

\section{Sample Collection}

Specimens of fish species common in and near the Santa Barbara Basin were

242 collected in the southern CCS during research cruises. Specimens were also caught by seine and by hook and line from the Scripps Pier (La Jolla, CA) and obtained from bait

244 barges in San Diego and Oxnard, CA (Tables S1, S2). 33 species of fish were collected between 2004 and 2013. The majority (87\%) of live fish were collected south of Point

246 Conception $\left(34.51^{\circ} \mathrm{N}\right.$, Tables S1, S2). A total of 490 sagittal otoliths from live-caught fish were analyzed, one per fish.

248 Otoliths were also obtained from the Fitch Otolith Collection at the Natural History Museum of Los Angeles County $($ LACM) $(n=408)$ and the Scripps Institution of

250 Oceanography (SIO) Otolith Collection $(n=7)$. A total of 415 otoliths from 22 species from museum collections were used and returned. Ancillary data, such as SL and

252 collection location, were largely absent for these otoliths.

\section{Otolith Groups}


Otolith Classification

Seven otolith groups were defined for this study: entire otoliths of Bathylagidae,

256 Engraulidae, Merlucciidae, Myctophidae, Sebastidae, and 'Other' fish, and broken otoliths of Bathylagidae. These groups were created to include the most common taxa

258 found in and near the SBB (Table S9). The group 'Other' contained fish species not in the previously defined taxonomic groups but known from CalCOFI ichthyoplankton

260 collections to be present in and near the SBB (Table S9). The group 'Broken Bathylagidae' includes Bathylagidae otoliths without the rostrum. This group was

262 included because the rostrum of Bathylagidae otoliths is fragile and easily broken and entire and broken Bathylagidae otoliths differ in shape.

\section{Otolith Data}

266 Morphometric (M) data were obtained for all otoliths (n=905) (Fig. 1). Element concentration and morphometric $(\mathrm{ME})$ data were obtained for a subset of all otoliths $(\mathrm{n}=$

268 143) (Fig. 1). M contained GEO and EF features for 905 otoliths from 46 species in seven taxonomic groups (Tables 1, S1). ME contained GEO, EF and ELM features from 143

270 otoliths from 12 species in six taxonomic groups (Tables 2, S2). In M, the group 'Other' contained otoliths from 21 species. In ME, the group 'Other' contained otoliths from only

272 one species, Sardinops sagax, and therefore this group was referred to as Clupeidae. The group 'Broken Bathylagidae' was in M but not ME because we assumed entire and

274 partial otoliths have the same elemental composition.

\section{Feature Transformation}

The majority of otolith features had a non-normal distribution (Kolmogorov-

278 Smirnov test) and/or inhomogeneous variance (Levene's test). Therefore, all features were log-transformed prior to statistical analysis. Even after transformation, the majority

280 of otolith features had a non-normal distribution and/or heteroskedastic variance, as found in other studies (Gillanders et al. 2001; Elsdon and Gillanders 2005). We used

282 transformed data in our analyses because the variances of transformed data departed less from normality than those of untransformed data. The departure from normality led us to

284 use the non-parametric RFA in addition to parametric DFA to classify otoliths. 
Otolith Classification

\section{Geometric Features}

Each GEO feature varied significantly between groups for both $\mathrm{M}$ and $\mathrm{ME}$

288 (ANOVA and non-parametric Kruskal-Wallis tests; Tables 3, S4, S5, S10; Figures 2, 3). This was the case when the significance level was set at 0.05 (Table 3 ) or with

290 Bonferroni corrections for multiple comparisons (Table S10). All GEO features were therefore retained for use in developing classification models. AspR and Ell were the

292 strongest discriminatory GEO features for $\mathrm{M}\left(F_{6,483}\right.$ statistics: $\left.A s p R=363.9, E l l=346.1\right)$ and ME (ANOVA, $\left.F_{5,137}: E l l=297.3, A s p R=247.1\right)($ Tables S4 and S5). Bathylagidae,

294 Engraulidae, and Broken Bathylagidae GEO features differed the most from GEO features of the other groups for M, while Clupeidae and Bathylagidae GEO features

296 differed the most from GEO features of the other groups for ME (Tukey HSD, Tables S6, S7).

Canonical function analysis resulted in two axes (Canonical Variables 1 and 2), which explained variation in the distribution of individual otoliths of the taxonomic

300 groups. The results were similar for $\mathrm{M}$ and $\mathrm{ME}$, with the difference due primarily to the larger sample size for M (905 otoliths) than ME (143 otoliths). Canonical Variables 1 and

3022 explained $59.5 \%$ and $27.6 \%$, respectively, of variation in the GEO features of the otoliths in M (Fig. S1). Canonical Variables 1 and 2 explained $73.4 \%$ and $19.6 \%$,

304 respectively, of variation in the GEO features of the otoliths in ME (Fig. S2). The aspect ratio of otoliths $(A s p R)$ and ellipticity $(E l l)$ were most positively associated with

306 Canonical Variable 1, while Roundness (Rnd) was most negatively associated with Canonical Variable 1. Extent (Ext) was most positively associated with Canonical

308 Variable 2 for M (Fig. S1) and minor Axis length $(m A L)$ with Canonical Variable 2 for ME (Fig. S2).

\section{Elliptic Fourier Features}

All EF features in M and all EF features except y29 in ME varied significantly between taxonomic groups (ANOVA, Tables 3, S4, S5; p < 0.05). Results of the non-

314 parametric Kruskal-Wallis test $(\mathrm{p}<0.05)$ were consistent with those of the ANOVA. Thus, the feature $y 29$ was the only EF feature excluded from the classification analysis.

316 The results were similar when the significance level reduced using the Bonferroni 
Otolith Classification

correction for multiple comparisons, although fewer EF features showed significant

318 variation between taxonomic groups (Table S10). The most discriminatory features for $\mathrm{M}$ were $y 1$ was the most discriminatory feature, followed by $x 3$ and $y 2$ (ANOVA, $F_{6,483}$

320 statistics: $y 1=51.1, x 3=23.1$, and $y 2=22.5$; Table S4). Those for ME were $y 2, x 9$ and $y 5$ (ANOVA, $F_{5,137}$ statistics: $y 2=18.0, x 9=16.8$, and $y 5=16.6$; Table S5). Post hoc

322 analysis of differences between EF feature variation among groups indicated that Merlucciidae and Engraulidae were most different from the other groups in $\mathrm{M}$ and

324 Clupeidae and Merlucciidae were most different from the other groups in ME (Tukey HD, Tables S6, S7).

326 The EF features (29 $x$ and $30 y$ descriptors) are plotted in relation to harmonic number for each taxonomic group (Fig. 4). For both $\mathrm{M}$ and $\mathrm{ME}$, otoliths from

328 Bathylagidae and Clupeidae had higher $x$ and $y$ EF descriptors than other taxa. Merlucciidae showed the greatest variability across the range of harmonics, while

330 Myctophidae showed the least variability. Myctophidae had the lowest $x$ and $y$ EF descriptors. Standard errors for EF descriptors for M were, in general, smaller than those

332 for ME, consistent with the differences in sample size (905 and 143 otoliths for M and ME, respectively).

334 The relationship between individual EF features and Canonical Variables 1 and 2 are shown in Figures S3 (M) and S4 (ME). Canonical Variable 1 captured 52.0\% and

$33644.5 \%$, for ME and M, respectively. Canonical Variable 2 captured $31.6 \%$ and $20.9 \%$ of the variability for $\mathrm{M}$ and $\mathrm{ME}$, respectively. Variables $x 3$ and $x 5$ were most positively

338 associated with Canonical Variable 1 for $M$ and most negatively associated with Canonical Variable 1 for ME.

\section{Element Concentration Features}

Element concentration ratios for the six taxonomic groups are shown in Figure 5. Sebastidae and Bathylagidae had high values of $\mathrm{Mg}: \mathrm{Ca}, \mathrm{Na}: \mathrm{Ca}$, and $\mathrm{Mn}: \mathrm{Ca}$. Merlucciidae

344 had high values of Mn:Ca and $\mathrm{K}: \mathrm{Ca}$ and Myctophidae low values of these two elemental ratios as well as of $\mathrm{Na}: \mathrm{Ca}$ and $\mathrm{Mg}: \mathrm{Ca}$. Engraulidae had low values of Sr:Ca and high

346 values of Li:Ca. Clupeidae had element concentration ratios in the mid-range of those for all other groups. Significant differences between taxonomic groups were found for $\mathrm{Li}: \mathrm{Ca}$, 
Otolith Classification

$348 \mathrm{Mg}: \mathrm{Ca}, \mathrm{Mn}: \mathrm{Ca}, \mathrm{Sr}: \mathrm{Ca}, \mathrm{Na}: \mathrm{Ca}$, and K:Ca (ANOVA and Kruskal-Wallis test, Table S5; $\mathrm{p}<0.05)$. Ba:Ca did not vary significantly between groups using either test and was

350 therefore was not used in classification models. The results were similar using a Bonferroni correction for multiple comparisons, though only $\mathrm{Mg}: \mathrm{Ca}, \mathrm{Na}: \mathrm{Ca}$ and $\mathrm{K}: \mathrm{Ca}$

352 remained significant using ANOVA (Table S10). $\mathrm{Mg}$ :Ca was the most discriminating ELM feature, followed by K:Ca and Na:Ca (ANOVA, $F_{5,137}$ statistics: $\mathrm{Mg}: \mathrm{Ca}=14.5$,

$354 \mathrm{~K}: \mathrm{Ca}=13.5$, and $\mathrm{Na}: \mathrm{Ca}=9.1) . \mathrm{K}: \mathrm{Ca}$ values were positively associated with Canonical Variable 1 and negatively associated with the Canonical Variable 2, while $\mathrm{Mg}: \mathrm{Ca}$ and

356 Na:Ca values were positively associated with both canonical variables (Fig. S5). Canonical Variables 1 and 2 captured $49.6 \%$ and 29\% of the variability, respectively.

358 Merlucciidae differed the most from the other taxa in elemental composition (Tukey HSD, Table S7).

\section{Factor Analysis}

362 The effect of fish size and collection year and location on otolith features was examined using one-way and multi-factor ANOVA. Otoliths from museum collections

364 that lacked ancillary data were excluded. Three categories of factors were used: five fish size ranges, four collection year ranges, and three collection regions (Table S8). ANOVA

366 was performed for each feature of the three types (GEO, EF, ELM). The three categories (fish size and collection year and location) were not as important as taxonomic group for

368 the large majority of GEO and EF features (Tables 3, S4, S5, S10). For ELM features, variability attributed to taxonomic group was greater than the variability attributed to any

370 of the measured factors for all but two features (multi-factor ANOVA, Table S5; p < 0.05). First, Sr:Ca varied more with collection year than taxonomic group. This pattern

372 appeared to be dominated by variability within the group Myctophidae. Myctophidae collected in 2010 had Sr:Ca concentrations that were almost twice as high as those

374 collected in 2012. However, only four Myctophidae were collected in 2010, all Protomyctophum crockeri, which was not sampled in 2012. Given the small sample size

376 and our inability to separate the effects of year and species for this feature, Sr:Ca was not excluded from the classification analysis. Second, K:Ca varied significantly with fish size

378 range. This result was also only observed in one group, Merlucciidae. The effect of fish 
Otolith Classification

size on $\mathrm{K}: \mathrm{Ca}$ could not be separated from the influence of species on $\mathrm{K}: \mathrm{Ca}$. Merlucciidae

380 otoliths were also significantly larger than those of any other group. We decided to not exclude K:Ca from the classification analysis. Factor analysis results using Bonferroni

382 correction for multiple comparisons yielded similar results (Table S10).

\section{Classification Models}

Our goal was to create models with the most success in classifying otoliths of

386 masked origin into taxonomic groups using only morphometric (M) or both morphometric and elemental composition (ME) data. We evaluated linear discriminant

388 function analysis (DFA) and random forest analysis (RFA) using cross validation.

Five sets of feature combinations were compared for otoliths in $\mathrm{M}$ (morphometric

390 data only): (i) GEO, (ii) EF, (iii) GEO, EF (vi) the DFA forward stepwise feature set (DFA10 SW), and (v) the RFA rank feature set (RFA10 Rank). Eight sets of feature

392 combinations were compared for otoliths in ME (morphometric and element data): (vi) GEO, (vii) EF, (viii) ELM, (ix) GEO, ELM, (x) GEO, EF, (xi) GEO, EF, ELM, (xii)

394 DFA10 SW, and (xiii) RFA10 Rank. Each set of features was tested using both DFA and RFA. RFA outperformed DFA in most cases (Table 4). RFA results are reported below

396 unless otherwise noted.

Classification models based on only one type of feature (i, ii, vi, vii, and viii

398 above) were tested first (Table 4). For both M and ME, GEO features outperformed both EF and ELM features. For M, the classifier using only GEO features had a 10-fold cross-

400 validation misclassification error of $14.6 \%$ compared to $25 \%$ when only EF features were used. For ME, the 10-fold cross validation misclassification error was $8 \%$ for the GEO-

402 based classifier, $13.2 \%$ for EF-based classifier, and 17.1\% for the ELM-based classifier.

Classification models based on two or three types of features (iii, ix, $\mathrm{x}$ and $\mathrm{xi}$

404 above) were then tested (Table 4). Classification based on both GEO and EF for M had a 10 -fold cross-validation misclassification error of $14.1 \%$, compared with $14.6 \%$ for a

406 classification model based on only one feature type (GEO). Classification of ME using all the features and types (GEO, EF, ELM) resulted in the best model, with a

408 misclassification error of $4.6 \%$. 
Otolith Classification

Knowing that classification success was greatest using all available types of

410 features (GEO and EF for M; GEO, EF and ELM for ME), we next examined if reducing the number of individual features would improve classification by reducing co-linearity

412 among features (Williams 1983). Both DFA stepwise and RFA rank procedures were used create classification models and rank the discriminatory power of individual features

414 as they were added. Starting with five features, classification success increased as additional features were added until an inflection point was reached at ten features. The

416 classification model with the highest success for $M$ contained ten input features, determined using the RFA rank procedure (RFA10 Rank). This model included 9 GEO

418 features and $1 \mathrm{EF}$ feature and had a misclassification error of $11.8 \%$ (Tables 4, 5). The classification model with the highest success for ME included ten features, determined

420 using the DFA stepwise procedure (DFA10 SW). This model had 7 GEO, 1 EF and 2 ELM features and a misclassification error of $3.7 \%$ (Tables 4,5$)$.

\section{Canonical Function Analysis}

424 Canonical function analysis was used to examine patterns in feature and group variation (Fig. 6). Canonical Variable 1 and 2 explained 51.5\% and 34.5\%, respectively,

426 of feature variation for $M$ and $59.0 \%$ and $27.3 \%$, respectively, of feature variation for ME. The aspect ratio of otoliths $(A s p R)$ and ellipticity $(E l l)$ were most positively

428 associated with Canonical Variable 1, while extent $(E x t)$ was most positively associated with canonical variable 2 for both M and ME (Fig. 6). In general, Engraulidae and

430 Merlucciidae were most strongly associated with positive values of both Canonical Variables 1 and 2. Myctophidae was most positively associated with negative Canonical

432 Variable 1 and positive Canonical Variable 2. Bathylagidae was also negatively associated with Canonical Variable 2.

\section{DISCUSSION}

The present study uses otolith morphology and elemental composition with two

438 classification methods to discriminate between otoliths of groups of fish found in and near the Santa Barbara Basin. We include elemental composition because otolith 
Otolith Classification

440 morphology may be altered between otolith formation and analysis. We found consistent differences of otolith features between groups. Classification models with greatest

442 success were based on the ten highest-ranked otolith features.

\section{Otolith Selection}

Our focus is on otoliths of fish from in and near the Santa Barbara Basin (SBB).

446 We selected species representative of fish common in this region over then entire water column, assuming that otoliths from those fish accumulate on the bottom of the SBB. The

448 large majority (87\%) of otoliths used in this study were from fish caught off the coast of Southern California, while the remaining fish were collected between Point Conception

450 and Southern Oregon or obtained from regional otolith collections. We included mesopelagic fish because they are abundant off Southern California and in the SBB

452 (Moser and Watson 2006; Davison et al. 2015). Mesopelagic fish are also important prey of fish, squid, sea birds, and marine mammals (Fitch and Brownell 1968; Pinkas et al.

454 1971; Markaida and Sosa-Nishizaki 2003). Recent, revised estimates of abundance of mesopelagic fish worldwide indicate their importance in the global ocean (Irigoien et al.

456 2014; Koslow et al. 2014; Davison et al. 2015).

The groups Bathylagidae, Engraulidae, Myctophidae, Merlucciidae, Sebastidae,

458 and 'Other' include 17 of the 20 most common species in and around the SSB. The taxonomic group 'Other' contained less common fish species that were not part of the

460 other five taxonomic groups, including sardine (Sardinops sagax) and bristlemouths (Vinciguerria lucetia). These groups include $95 \%$ of the total number of fish larvae

462 enumerated in CalCOFI 505- $\mu$ m-mesh net tows in the southern California Current System since 1951 (Table S9).

464 Ichthyoplankton collected at stations in the center of the SBB (CalCOFI Lines 81.5-82 and Stations 46-47) are representative of ichthyoplankton collected over most of

466 the CalCOFI grid, with a few exceptions. SBB ichthyoplankton include more Bathylagidae and Sebastidae and fewer Merlucciidae than other areas of the CalCOFI

468 grid (Table S9). We assume that the taxa whose otoliths were used for morphometric analysis (M) in this study were representative of fish common in the SBB. Although only 
Otolith Classification

470 a subset of otoliths $(n=143)$ was analyzed for elemental composition, it had representatives from each of the taxonomic groups.

472

\section{Otolith Features}

We are unaware of other studies that have developed classification models for mixtures of otoliths of pelagic, mesopelagic and demersal fishes. Nor are we aware of

476 studies that have developed classification models for otoliths based on both morphology and elemental composition. The three types of features (GEO, EF and ELM) in our study

478 differed in their power to discriminate between otoliths from different taxonomic groups. Bathylagidae and Clupeidae were best separated from other taxonomic groups using

480 GEO features, while Merlucciidae and Engraulidae were best separated from one another using EF and ELM features. Myctophidae and Sebastidae had similar GEO and EF

482 features. While ELM features differed significantly between Bathylagidae and Myctophidae, Clupeidae overlapped with both of these taxa, indicating that there was no

484 strong pattern in otolith elemental composition between pelagic and mesopelagic fish (Table S7).

486 Twelve geometric features were used to define the geometric (GEO) morphology of each otolith. Of these features, six (Sol, Ecc, Ell, Rnd, Ext, AspR) were dimensionless

488 yet indirectly related to otolith size, as other studies have found (e.g., Zorica et al. 2010). The remaining six GEO features ( $A, P, M A L, m A L, E q D$, Conv $A$ ) had either linear or

490 areal dimensions and thus were directly related to otolith size. More variability of the dimensionless GEO features was explained by taxonomic group than by otolith size or

492 any other factor (Tables S4, S5). The most useful GEO features for discriminating between taxa were the dimensionless features Ell and AspR. Nevertheless, both

494 dimensionless and size-related features ranked sufficiently high to be included in the final classification models (i.e., DFA10 SW, RFA10 Rank). Studies using otolith morphology

496 to discriminate between fish stocks and populations have avoided the use of size-related features in preference of dimensionless features with little or no relation to size (e.g.,

498 Tuset et al. 2003; Zorica et al. 2010). Our objective, to classify otoliths into taxonomic groups, warranted our use of size-related GEO features, which have strong discriminatory 500 power between groups that differ in morphology (Reist 1986). 
Otolith Classification

We normalized the elliptic Fourier (EF) descriptors by otolith size. One hundred 502 evenly spaced boundary pixels comprised the chain-code. Thus, spatial resolution of the chain code depended on otolith size. However, our classification results indicate that the

504 low harmonic $(\mathrm{n} \leq 5)$ descriptors, representing the basic shape of an otolith, were most important (Table 4). We conclude that 100 evenly spaced chain-code pixels were

506 sufficient to describe the contour of each otolith, independent of otolith size. This is also consistent with the rapid decline in EF descriptor values with increasing harmonic

508 number (Fig. 4). Our use of 30 harmonics captured $>99.99 \%$ of the mean cumulated Fourier power (Mérigot et al. 2007; Stransky et al. 2008). Each of the final two

510 classification models used only one EF feature (Table 5). EF features have been observed to vary within species (Campana and Casselman 1993) and between species (Stransky

512 and MacLellan 2005; Kemp et al. 2011). We also observed that variability in EF features was better explained by taxonomic group than by otolith size, year or location (Table S4,

514 S5). EF features varied most for Merlucciidae and least for Myctophidae (Fig. 4), likely due to the rugose and high aspect ratio of Merlucciidae otoliths and the smooth and

516 circular nature of Myctophidae otoliths (Jones and Morales 2014).

Otolith shape analysis has been used to taxonomically classify otoliths in gut

518 contents (Casper et al. 2006) and in paleoecological studies (Parisi-Baradad et al. 2005; Reichenbacher et al. 2007; Disspain et al. 2015). Our results are consistent with these and

520 other studies showing that otolith morphology can be used for taxonomic classification (Tuset et al. 2008; Zorica et al. 2010) and that otolith shape is principally under genetic

522 control (Lombarte et al. 2010; Reichenbacher and Reichard 2014).

The large differences we observed in the elemental composition of otoliths

524 between taxonomic groups are consistent with studies showing otolith elemental composition varies between species (Gillanders and Kingsford 2003; Swearer et al. 2003;

526 Hamer and Jenkins 2007). We found Mg to most strongly discriminate between taxonomic groups, followed by $\mathrm{K}, \mathrm{Na}, \mathrm{Sr}$ and $\mathrm{Mn}$. An extensive analysis of the elemental

528 composition of otoliths, most of which were from European waters, also observed variability between species within a region, particularly in $\mathrm{Sr}, \mathrm{Mg}, \mathrm{Mn}$, and $\mathrm{Ba}$ (Chang 530 and Geffen 2013). We note that $\mathrm{Sr}$ and $\mathrm{Mg}$ were strong discriminators between otoliths 


\section{Otolith Classification}

from fish in both the southern California Current System (present study) and European

532 waters (Chang and Geffen 2013).

We observed stronger effects on elemental composition by taxonomic group than

534 year and location, consistent with variation in the species-specific physiology of trace element incorporation in the otolith (Chang and Geffen 2013). However, otolith

536 elemental composition may also vary between taxa due to variation in habitat use and diet (Ruttenberg et al. 2005; Gillanders 2005). The combined variability in elemental

538 composition related to species, date, and location preclude generalizations about the abundances of elements in regard to species, date and location (Campana and Thorrold

540 2001; Chang and Geffen 2013).

We did not observe a clear pattern of the element concentrations among pelagic,

542 mesopelagic and demersal fishes. Otoliths of benthic fish species have been observed to possess higher concentrations of Sr and lower levels of other trace elements than otoliths

544 of pelagic and demersal species (Swearer et al. 2003, Hamer and Jenkins 2007).

Otolith elemental analysis has been most widely used to infer about stocks

546 (Campana et al. 2000; Tanner et al. 2016), migration pathways (Hamer et al. 2006) and natal origins (Thorrold et al. 2001). Our results and those of other studies support the

548 hypothesis that, with appropriate background data and within appropriate ranges of species, date and location, the concentrations of certain elements can be used in the

550 taxonomic classification of otoliths of unknown origin.

We used elemental composition in addition to morphology to distinguish between

552 taxonomic groups because of the possibility that otolith morphology may be altered between otolith formation and analysis whereas the elemental composition is unlikely to

554 change. Our methods will be useful for the classification fossil otoliths recovered from Santa Barbara Basin sediments. The accuracy of classification relies on the preservation

556 of the features in the archaeological or paleontological otolith samples, which may be altered between otolith formation and analysis (Proctor and Thresher 1998). Alteration of

558 otoliths may result from physical, chemical or biological processes that can occur during ingestion, gut passage, burial and sampling (Nicholson 1996; Zohar et al 2008; Disspain

560 et al. 2015). To reduce potential bias due to otolith shape alteration, we included elemental composition in our analyses. Diagenetic processes have been shown to not 
Otolith Classification

562 have significantly altered the elemental composition of fossil otoliths, when compared to modern specimens (Degens 1969; Kern 2012; Cook 2015; Cook 2016).

\section{Otolith Classification}

We sought to classify otoliths of unknown origin based on their morphology and elemental composition. We used distinguishing features and two types of classification

568 models. We tested our models using masked otoliths and cross-validation. The classifiers we developed are useful for the analysis of otoliths from Santa Barbara Basin sediments,

570 which lie beneath waters containing fish species represented by those in this study. The methods we used may be of general interest for the development of classifiers to analyze

572 otoliths of unknown origin from other sources including feces, gut contents, middens and sediments.

$574 \quad$ A variety of methods have been used to classify otoliths (e.g., Edmonds et al. 1991; Gillanders and Kingsford 2003; Mercier et al. 2011). Linear discriminant function

576 analysis (DFA) has been used most often. Machine learning, including random forest analysis (RFA) and artificial neural networks (ANN), has been used in medical (Jiang et

578 al. 2007), ecological (Perdiguero-Alonso et al. 2008) and otolith (Mercier et al. 2011) pattern recognition studies. RFA was used with otolith elemental composition to classify

580 stocks of freshwater marine fishes (Paillon et al. 2014, Loewen et al. 2015). These studies focused on the elemental composition of otoliths.

582 We compared combinations of GEO, EF and ELM features for classifying otoliths of masked taxonomic group (Table 4). We built on prior studies, in which multiple types

584 of features were used to increase discrimination power (Kemp et al. 2011, Longmore 2010), by also using two classification methods. RFA outperformed DFA for M using

586 GEO and EF features singly and in combination (Table 4). RFA also outperformed DFA for ME using all three types of features singly or combined, except for one case (Table

588 4). These results are consistent with other studies (Jiang et al. 2007; Perdiguero-Alonso et al. 2008; Mercier et al. 2011). Our results are also consistent with the suggestion that

590 RFA is best for complex data (Mercier et al. 2011). RFA may outperform DFA due to inherent differences in their mechanisms. RFA uses ensemble decisions and sequential

592 hyperplanes to partition space, making more complex decision boundaries possible, while 
Otolith Classification

DFA is limited by the use of a linear hyperplane (Williams 1983). However, DFA was

594 the best model for ME, although the increase in classification success over RFA was small $(1.2 \%)$.

596 Morphological (GEO) features outperformed both elliptic Fourier (EF) and elemental composition (ELM) features when each was tested independently using cross

598 validation (Table 4). This result differs from otolith classification studies that have found EF or ELM features often superior to GEO features (Kemp et al. 2011; Longmore 2010).

600 This disparity may be due to our focus on distinguishing between taxonomic groups while other studies focused on distinguishing within species and between populations and

602 stocks, where morphology may be less informative than elemental composition (Campana and Casselmann 1993; Campana et al. 2000; Campana and Thorrold 2001;

604 Geffen et al. 2003; Swan et al. 2006; Chang and Geffen 2013).

Most otolith classification studies have focused on a single type of feature or

606 compare the classification success between types of features (Milton and Chenery 2001; Lin et al. 2007; Marohn et al. 2009). When different types of features are used together,

608 classification success can increase significantly (Tracey et al. 2006; Burke et al. 2008). We tested 5 to 12 features of two or three types (GEO, EF, ELM) for our final

610 classification models. Discrimination power approached an asymptote at 10 input features for both M and ME. Similarly, Mercier et al. (2011) found 8-10 input features to

612 be optimal. Our final classification models for $\mathrm{M}$ and ME each contained at least one feature from all available categories, highlighting the value for discrimination by using a

614 limited but sufficient number of different types of input features.

We show that otolith morphology and elemental composition can be used together

616 to distinguish taxonomic groups of fish found in and near the Santa Barbara Basin. Morphological and elemental composition features varied significantly among taxonomic

618 groups. Their use in DFA and RFA classifiers provided strong discriminatory power. In general, RFA was a superior to DFA, especially for ME, which contained both

620 morphometric and elemental composition features. The highest classification success, as judged by cross validation, was obtained by using the ten features, of all types, that

622 contributed most to discrimination between taxonomic groups and by limiting the total number of features provided. The methods used here may have a wider application to the 
Otolith Classification

624 classification of otoliths from groups of fish from other areas and of other types of objects based on multiple types of features.

626

Acknowledgments. We thank Pete Davison, Noelle Bowlin, Amanda Netburn, Barb

628 Javier, Keith Sakuma and John Field on the various CalCOFI, CCE-LTER, NOAA, and SIO research cruises for providing fish. We acknowledge Rick Feeney at the LACM and

630 H.J. Walker at SIO for loaning otoliths from the collections they manage. Mark Morales provided essential help dissecting, cleaning, photographing, and classifying otoliths. We

632 thank Leah Houghton and Simon Thorrold at the Woods Hole Oceanographic Institution for analyzing chemical elements in otoliths. We thank Marie A. Roch and Bryan Black

634 for their guidance and comments on the manuscript. This research was supported by California Sea Grant (Award NOAA NA14OAR4170075 CHECKLEY to David

636 Checkley) and the National Science Foundation (NSF Graduate Research Fellowship to William Jones).

638

\section{LITURATURE CITED}

Avigliano, E., Martinez, C.F.R., and Volpedo, A.V. 2014. Combined use of otolith microchemistry and morphometry as indicators of the habitat of the silverside (Odontesthes bonariensis) in a freshwater-estuarine environment. Fish. Res. 149: $55-60$.

Bath, G.E., Thorrold, S.R., Jones, C.M., Campana, S.E., McLaren, J.W., and Lam, J.W. 2000. Strontium and barium uptake in aragonitic otoliths of marine fish. Geochim. Cosmochim. Ac. 64(10): 1705-1714.

652 Breiman, L. 2001. Random forests. Mach. Learn. 45(1): 5-32.

Brown, M.B. and Forsythe, A.B. 1974. Robust tests for the equality of variances. J. Am. Stat. Assoc. 69(346): 364-367. 
Otolith Classification

Burke, N., Brophy, D., and King, P.A. 2008. Otolith shape analysis: its application for discriminating between stocks of Irish Sea and Celtic Sea herring (Clupea harengus) in the Irish Sea. ICES J. Mar. Sci.: J. Cons. 65(9): 1670-1675.

658 Campana, S.E. 1999. Chemistry and composition of fish otoliths: pathways, mechanisms and applications. Mar. Ecol. Prog. Ser. 188: 263-297.

660 Campana, S.E., and Casselman, J.M. 1993. Stock discrimination using otolith shape analysis. Can. J. Fish. Aquat. Sci. 50(5): 1062-1083.

662 Campana, S.E., and Neilson, J.D. 1985. Microstructure of fish otoliths. Can. J. Fish. Aquat. Sci. 42(5): 1014-1032.

664 Campana, S.E., and Thorrold, S.R. 2001. Otoliths, increments, and elements: keys to a comprehensive understanding of fish populations? Can. J. Fish. Aquat. Sci. 58(1):

$666 \quad 30-38$.

Campana, S.E., Chouinard, G.A, Hanson, J.M., Frechet, A., and Brattey, J. 2000. Otolith elemental fingerprints as biological tracers of fish stocks. Fish. Res. 46(1): 343357.

670 Casper, R.M., Gales, N.J., Hindell, M.A., and Robinson, S.M. 2006. Diet estimation based on an integrated mixed prey feeding experiment using Arctocephalus seals.

672 J. Exp. Mar. Biol. Ecol. 328(2): 228-239.

Cook, P.K., Languille, M.A., Dufour, E., Mocuta, C., Tombret, O., Fortuna, F., and Bertrand, L. 2015. Biogenic and diagenetic indicators in archaeological and modern otoliths: Potential and limits of high definition synchrotron micro-XRF elemental mapping. Chem. Geol. 414: 1-15.

Cook, P.K., Dufour, E., Languille, M.A., Mocuta, C., Réguer, S., and Bertrand, L. 2016. Strontium speciation in archaeological otoliths. J. Anal. At. Spectrom. 31(3): 700711.

680 Chang, M.Y., and Geffen, A.J. 2013. Taxonomic and geographic influences on fish otolith microchemistry. Fish. Fish. 14(4): 458-492.

682 Davison, P.C., Lara-Lopez, A., and Koslow, J.A. 2015. Mesopelagic fish biomass in the southern California Current ecosystem. Deep-Sea Res. PT II 112:129-142.

684 Degens, E.T. 1969. Molecular structure and composition of fish otoliths. Mar. Biol. 2: 105-113. 
Otolith Classification

686 Disspain, M.C., Ulm, S., and Gillanders B.M. 2015. Otoliths in archaeology: Methods, applications and future prospects. J. Archaeol. Sci. Reports. In press.

688 Edmonds, J.S., Caputi, N., and Morita, M. (1991) Stock discrimination by trace-element analysis of otoliths of orange roughy (Hoplostethus atlanticus), a deep-water marine teleost. Mar. Freshw. Res. 42(4): 383-389.

Elsdon, T.S., and Gillanders, B.M. 2003. Reconstructing migratory patterns of fish based on environmental influences on otolith chemistry. Rev. Fish. Biol. Fisher. 13(3): 217-235.

694 Elsdon, T.S., and Gillanders, B.M. 2005. Alternative life-history patterns of estuarine fish: barium in otoliths elucidates freshwater residency. Can. J. Fish. Aquat. Sci. 62(5): 1143-1152.

Field, D.B., Baumgartner, T.R., Ferreira, V., Gutierrez, D., Lozano-Montes, H., et al. 2009. Chapter 4. Variability from scales in marine sediments and other historical records. In Checkley, Jr., D.M., Alheit, J., Oozeki, Y., Roy, C., eds. 2009. Climate Change and Small Pelagic Fish. Cambridge, United Kingdom: Cambridge University Press. 372 pp.

Fitch, J.E., and Brownell, Jr. R.L. 1968. Fish otoliths in cetacean stomachs and their importance in interpreting feeding habits. J. Fish. Res. Board. Can. 25(12): 25612574.

Ferguson, G.J., Ward, T.M., and Gillanders, B.M. 2011. Otolith shape and elemental composition: Complementary tools for stock discrimination of mulloway (Argyrosomus japonicus) in southern Australia. Fish. Res. 110(1): 75-83.

Geffen, A.J., Jarvis, K., Thorpe, J.P., Leah, R.T., and Nash, R.D.M. 2003. Spatial differences in the trace element concentrations of Irish Sea plaice Pleuronectes platessa and whiting Merlangius merlangus otoliths. J. Sea. Res. 50(2): 247-256.

Gillanders, B.M. 2005. Using elemental chemistry of fish otoliths to determine connectivity between estuarine and coastal habitats. Estuar. Coast. Shelf S. 64(1): 47-57.

714 Gillanders, B.M, and Kingsford, M.J. 2003. Spatial variation in elemental composition of otoliths of three species of fish (family Sparidae). Estuar. Coast. Shelf S. 57(5): 1049-1064. 
Otolith Classification

Gillanders, B.M., Sanchez $\square$ Jerez, P., Bayle $\square$ Sempere, J., and Ramos $\square$ Espla, A. 2001.

718

720

722

724

726

728

730

732

734

Jones, W.A., and Morales, M.M. 2014. Catalog of Otoliths of Select Fishes from the real and pseudo microRNA precursors using random forest prediction model with combined features. Nucleic Acids Res. 35(suppl 2): W339-W344.

Irigoien, X., Klevjer, T.A., Rostad, A., Martinez, U., Boyra, G., et al. 2014. Large mesopelagic fishes biomass and trophic efficiency in the open ocean. Nature Comm. doi: 10.1038/ncomms4271.

Jiang, P., Wu, H., Wang, W., Ma, W., Sun, X., and Lu, Z. 2007. MiPred: classification of California Current System. Scripps Institution of Oceanography, UC San Diego. http://escholarship.org/uc/item/5m69146s.

736 Kemp, J., Swearer, S.E., Jenkins, G.P., and Robertson, S. 2011. Otolith chemistry is more accurate than otolith shape in identifying cod species (genus Pseudophycis) in the diet of Australian fur seals (Arctocephalus pusillus doriferus). Can. J. Fish. Aquat. Sci. 68(10): 1732-1743.

Kern, Z., Kázmér, M., Bosnakoff, M., Váczi, T., Bajnóczi, B., and Katona, L. 2012. Incremental growth and mineralogy of Pannonian (Late Miocene) sciaenid otoliths: paleoecological implications. Geol. Carpath. 63(2): 175-178.

Koslow, J.A., Davison, P., Lara-Lopez, A., and Ohman, M.D. 2014. Epipelagic and mesopelagic fishes in the southern California Current System: Ecological interactions and oceanographic influences on their abundance. J. Mar. Sys. 138: 20-28.

Kuhl, F.P., and Giardina, C.R. 1982. Elliptic Fourier features of a closed contour. 
Otolith Classification

748

750

752

754

756

758

760

762

764

766

768

770

772

774

776

778

Comput. Vision Graph. 18(3):236-258.

Kohavi, R., 1995. A study of cross-validation and bootstrap for accuracy estimation and model selection. Proc. $14^{\text {th }}$ Intern. Joint Confer. Art. Intel. 14(2): 1137-1145.

Lilliefors, H.W. 1967. On the Kolmogorov-Smirnov test for normality with mean and variance unknown. J. Am. Stat. Assoc. 62(318): 399-402.

Lin, S.H., Chang, C.W., Iizuka, Y., and Tzeng W.N. 2007. Salinities, not diets, affect strontium/calcium ratios in otoliths of Anguilla japonica. J. Exp. Mar. Biol. Ecol. 341(2): 254-263.

Loewen, T.N., Reist, J.D., Yang, P., Koleszar, A., Babaluk, J.A., Mochnacz, N., and Halden, N.M. 2015. Discrimination of northern form Dolly Varden Char (Salvelinus malma malma) stocks of the North Slope, Yukon and Northwest Territories, Canada via otolith trace elements and 87 Sr/86 Sr isotopes. Fish. Res. 170: $116-124$.

Lombarte, A,. Palmer, M., Matallanas, J., Gómez-Zurita, J., and Morales-Nin, B. 2010. Ecomorphological trends and phylogenetic inertia of otolith sagittae in Nototheniidae. Environ. Biol. Fish. 89(3-4): 607-618.

Longmore, C., Fogarty, K., Neat, F., Brophy, D., Trueman, C., Milton, A., and Mariani, S. 2010. A comparison of otolith microchemistry and otolith shape analysis for the study of spatial variation in a deep-sea teleost, Coryphaenoides rupestris. Environ. Biol. Fish. 89(3-4): 591-605.

Lowry, M.S. 2011. Photographic Catalog of California Marine Fish Otoliths: Prey of California Sea Lions (Zalophus californianus). NOAA Tech. Memo. NMFS SWFSC 496: 1-142.

Markaida, U., and Sosa-Nishizaki, O. 2003. Food and feeding habits of jumbo squid Dosidicus gigas (Cephalopoda: Ommastrephidae) from the Gulf of California, Mexico. J. Mar. Biol. Assoc. UK 83(03): 507-522.

Marohn, L., Prigge, E., Zumholz, K., Klügel, A., Anders, H., and Hanel, R. 2009. Dietary effects on multi-element composition of European eel (Anguilla anguilla) otoliths. Mar. Biol. 156(5): 927-933.

Mebatsion, H.K., Paliwal, J., and Jayas, D.S. 2012. Evaluation of variations in the shape of grain types using principal components analysis of the elliptic Fourier 
Otolith Classification

descriptors. Comput. Electron. Agr. 80: 63-70.

780 Mercier, L., Darnaude, A.M., Bruguier, O., Vasconcelos, R.P., Cabral, H.N., Costa, M.J., Lara, M., Jones, D.L., and Mouillot, D. 2011. Selecting statistical models and

782 variable combinations for optimal classification using otolith microchemistry. Ecol. Appl. 21(4):1352-1364.

784 Mérigot, B., Letourneur, Y., and Lecomte-Finiger, R. 2007. Characterization of local populations of the common sole Solea solea (Pisces, Soleidae) in the NW Mediterranean through otolith morphometrics and shape analysis. Mar. Biol. 151(3): 997-1008.

788 Milton, D.A., and Chenery, S.R. 2001. Sources and uptake of trace metals in otoliths of juvenile barramundi (Lates calcarifer). J. Exp. Mar. Biol. Ecol. 264(1): 47-65.

790 Moser, H.G., and Watson, W. 2006. Ichthyoplankton. In: Allen, L.G., Pondella, D.J., and Horn, M.H. (eds) Ecology of California marine fishes. University of California Press, Berkeley, CA. p. 269-319.

Nicholson, R.A. 1996. Bone degradation, burial medium and species representation: debunking the myths, an experiment-based approach. J. Arch. Sci. 23(4): 513533.

796 Nolf, D. 1995. Studies on fossil otoliths - the state of the art. In Secor, D.H., Dean, J.M., and Campana, S.E. Recent Developments in Fish Otolith Research, pp 513-544.

798 Paillon, C., Wantiez, L., Kulbicki, M., Labonne, M., and Vigliola, L. 2014. Extent of Mangrove Nursery Habitats Determines the Geographic Distribution of a Coral Reef Fish in a South-Pacific Archipelago. PLoS ONE 9: e105158.

Parisi-Baradad, V., Lombarte, A., García-Ladona, E., Cabestany, J., Piera, J., and Chic, O. 2005. Otolith shape contour analysis using affine transformation invariant wavelet transforms and curvature scale space representation. Mar. Freshw. Res. 56(5): 795-804.

Pierce, G. J., Thomson, P.M., Miller, A., Diack, J.S.W., Miller, D., and Boyle, P.R. 1991. 806 Seasonal variation in the diet of common seals (Phoca vitulina) in the Moray Firth area of Scotland. J. Zool. 223(4): 641-652.

808 Perdiguero-Alonso, D., Montero, F.E., Kostadinova, A., Raga, J.A., and Barrett J. 2008. Random forests, a novel approach for discrimination of fish populations using 
parasites as biological tags. Int. J. Parasitol. 38(12): 1425-1434.

Pinkas, L. 1971. Food habits study. Fish. Bull. 152:5-10.

812 Popper, A.N., Ramcharitar, J., and Campana, S.E. 2005. Why otoliths? Insights from inner ear physiology and fisheries biology. Mar. Freshw. Res. 56(5): 497-504.

814 Proctor, C.H., and Thresher, R.E. 1998. Effects of specimen handling and otolith preparation on concentration of elements in fish otoliths. Mar. Biol. 131(4): 681-

$816 \quad 694$.

Reichenbacher, B., Sienknecht, U., Küchenhoff, H., and Fenske, N. 2007 Combined 818 otolith morphology and morphometry for assessing taxonomy and diversity in fossil and extant killifish (Aphanius, Prolebias). J. Morphol. 268(10): 898-915.

820 Reichenbacher, B, and Reichard, M. 2014. Otoliths of Five Extant Species of the Annual Killifish Nothobranchius from the East African Savannah. PLoS ONE 10: e112459.

Reist, J.D. 1986. An empirical evaluation of coefficients used in residual and allometric adjustment of size covariation. Can. J. Zoolog. 64(6): 1363-1368.

Rooker, J.R., Secor, D.H., Zdanowicz, V.S., and Itoh, T. 2001. Discrimination of northern bluefin tuna from nursery areas in the Pacific Ocean using otolith chemistry. Mar. Ecol. Prog. Ser. 218: 275-282.

828 Ruttenberg, B.I., Hamilton, S.L., Hickford, M.J., Paradis, G.L., Sheehy, M.S., Standish, J.D., Ben-Tzvi, O., and Warner R.R. 2005. Elevated levels of trace elements in cores of otoliths and their potential for use as natural tags. Mar. Ecol. Prog. Ser. 297: $273-281$.

832 Skrivanek, A., and Hendy, I.L. 2015. A 500 year climate catch: Pelagic fish scales and paleoproductivity in the Santa Barbara Basin from the Medieval Climate Anomaly to the Little Ice Age (AD 1000-1500). Quaternary International 387: 3645.

836 Soutar, A., and Isaacs, J.D. 1969. History of fish populations inferred from fish scales in anaerobic sediments off California. Rep. Cal. Coop. Oceanic Fish. Invest. 13: 6370

Stransky, C., and MacLellan, S.E. 2005. Species separation and zoogeography of redfish and rockfish (genus Sebastes) by otolith shape analysis. Can. J. Fish. Aquat. Sci. 
Otolith Classification

62(10): 2265-2276.

842 Stransky, C., Murta, A.G., Schlickeisen, J., and Zimmermann, C. 2008. Otolith shape analysis as a tool for stock separation of horse mackerel (Trachurus trachurus) in the Northeast Atlantic and Mediterranean. Fish. Res. 89(2): 159-166.

Swan, S.C., Geffen, A.J., Morales-Nin, B., Gordon, J.D., Shimmield, T., Sawyer, T., and 846 Massutí E. 2006. Otolith chemistry: an aid to stock separation of Helicolenus dactylopterus (bluemouth) and Merluccius merluccius (European hake) in the Northeast Atlantic and Mediterranean. ICES J. Mar. Sci.: J. Cons. 63(3): 504-513.

Swearer, S.E., Forrester, G.E., Steele, M.A., Brooks, A.J., and Lea, D.W. (2003) Spatio850 temporal and interspecific variation in otolith trace-elemental fingerprints in a temperate estuarine fish assemblage. Estuar. Coast. Shelf S. 56(5): 1111-1123.

852 Tanner, S.E., Reis-Santos, P., and Cabral, H.N. 2016. Otolith chemistry in stock delineation: A brief overview, current challenges and future prospects. Fish. Res. 173:206-213.

Thorrold, S.R., Latkoczy, C., Swart, P.K., and Jones, C.M. 2001. Natal homing in a marine fish metapopulation. Science, 291(5502): 297-299.

Tracey, S.R., Lyle, J.M., and Duhamel, G. 2006. Application of elliptic Fourier analysis 858 of otolith form as a tool for stock identification. Fish. Res. 77(2): 138-147.

Tuset, V.M., Lozano, I.J., Gonzalez, J.A., Pertusa, J.F., and García $\square$ Díaz, M.M. 2003. Shape indices to identify regional differences in otolith morphology of comber, Serranus cabrilla (L., 1758). J. Appl. Ichthyol. 19(2): 88-93.

862 Williams, B.K. 1983. Some observations of the use of discriminant analysis in ecology. Ecology, 1283-1291.

864 Zhang, C., Ye, Z., Wan, R., Ma, Q., and Li, Z. 2014. Investigating the population structure of small yellow croaker (Larimichthys polyactis) using internal and external features of otoliths. Fish. Res. 153: 41-47.

Zohar, I., Belmaker, M., Nadel, D., Gafny, S., Goren, M., Hershkovitz, I., and Dayan, T. 868 2008. The living and the dead: How do taphonomic processes modify relative abundance and skeletal completeness of freshwater fish? Palaeogeogr. Palaeoclimatol. Palaeoecol. 258(4): 292-316.

Zorica, B., Sinovčić, G., and Keč, V.Č. 2010. Preliminary data on the study of otolith 


\section{Otolith Classification}

872 morphology of five pelagic fish species from the Adriatic Sea (Croatia). Acta. Adriat. 51(1): 89.

874 
Otolith Classification

\section{Tables and Figures}

876

Figure 1

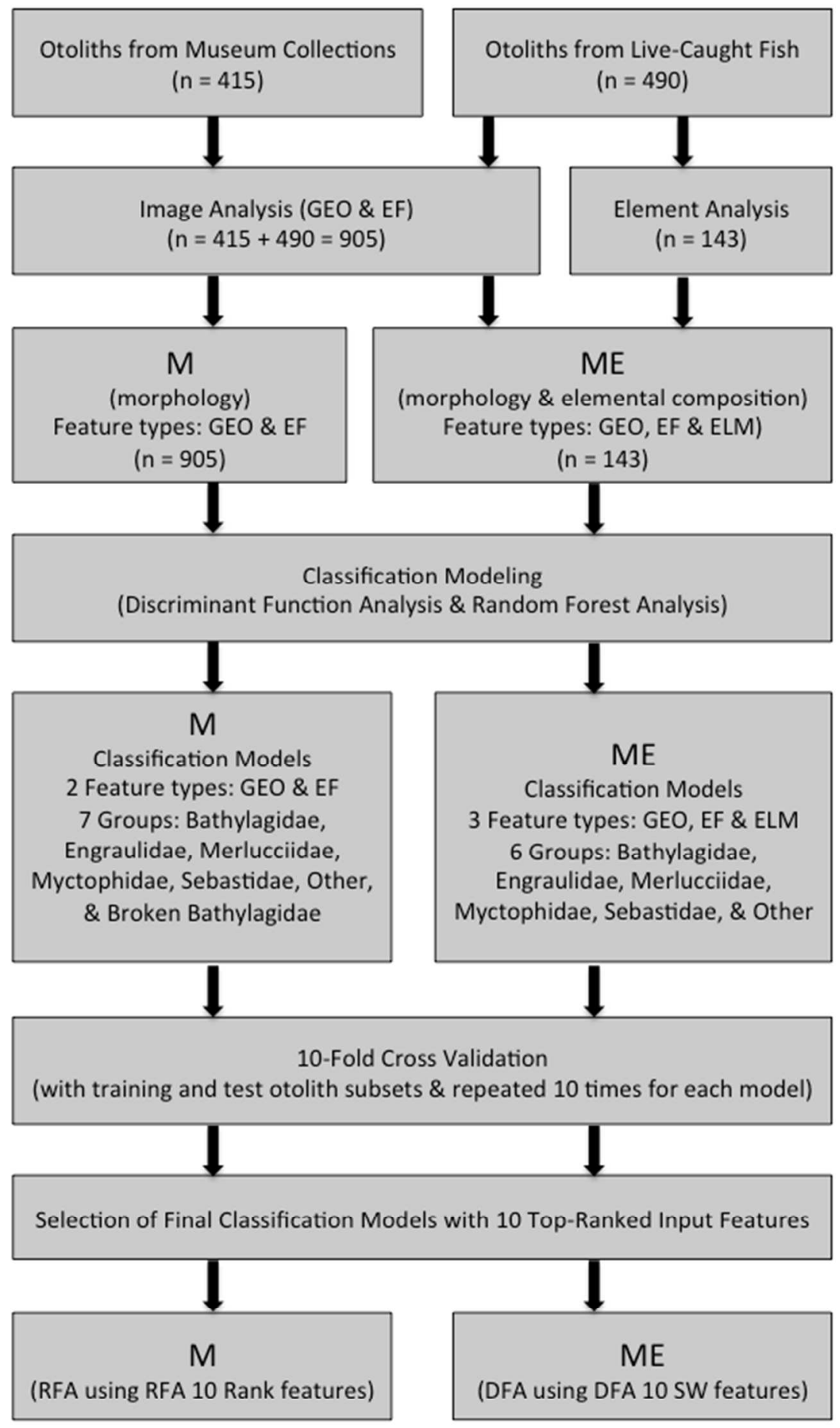

878

Page 32 of 44

https://mc06.manuscriptcentral.com/cjfas-pubs 


\section{Otolith Classification}

Figure 1. Flow chart of otolith analysis and creation of classification models. Feature 880 types are geometric (GEO), elliptical Fourier (EF) and element (ELM) concentration. Groups refer to categories of fish species common in and near the Santa Barbara Basin.

882 M refers to classification models based otoliths $(n=905)$ with only morphometric feature types (GEO \& EF). ME refers to classification models based on otoliths $(n=143)$ with

884 both morphometric and element concentration feature types (GEO, EF \& ELM). Discriminant function analysis (DFA), with stepwise (SW) feature selection, and random

886 forest analysis (RFA), with rank-based feature selection, were used. The 10-fold cross validation was performed 100 times on each classifier to estimate classification error. The 888 ten top-ranked features available in $\mathrm{M}$ and $\mathrm{ME}$ were used to create the final classifiers. See text for detail.

890 
Otolith Classification

Figure 2

894

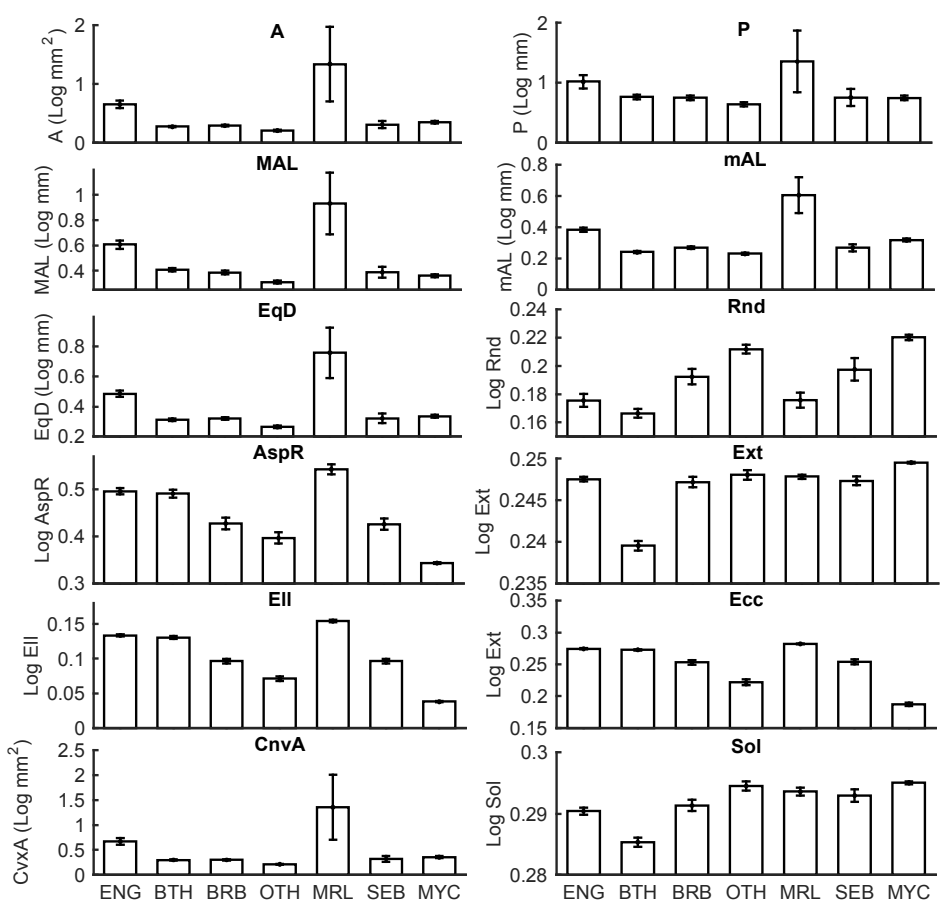

Figure 2. Mean and standard error of log-transformed geometric otolith features for different taxonomic groups of fish from the southern California Current System for $\mathrm{M}(\mathrm{n}=905)$. ENG $=$ Engraulidae $(\mathrm{n}=82)$, BTH $=$ Bathylagidae $(\mathrm{n}=130), \mathrm{BRB}=$ Broken Bathylagidae $(\mathrm{n}=51)$, OTH $=$ other $(\mathrm{n}=231), \mathrm{MRL}=$ Merlucciidae $(\mathrm{n}=19), \mathrm{SEB}=$ Sebastidae $(\mathrm{n}=24), \mathrm{MYC}=$ Myctophidae $(n=368)$. Feature abbreviations can be found in Table S3. 
Otolith Classification

Figure 3
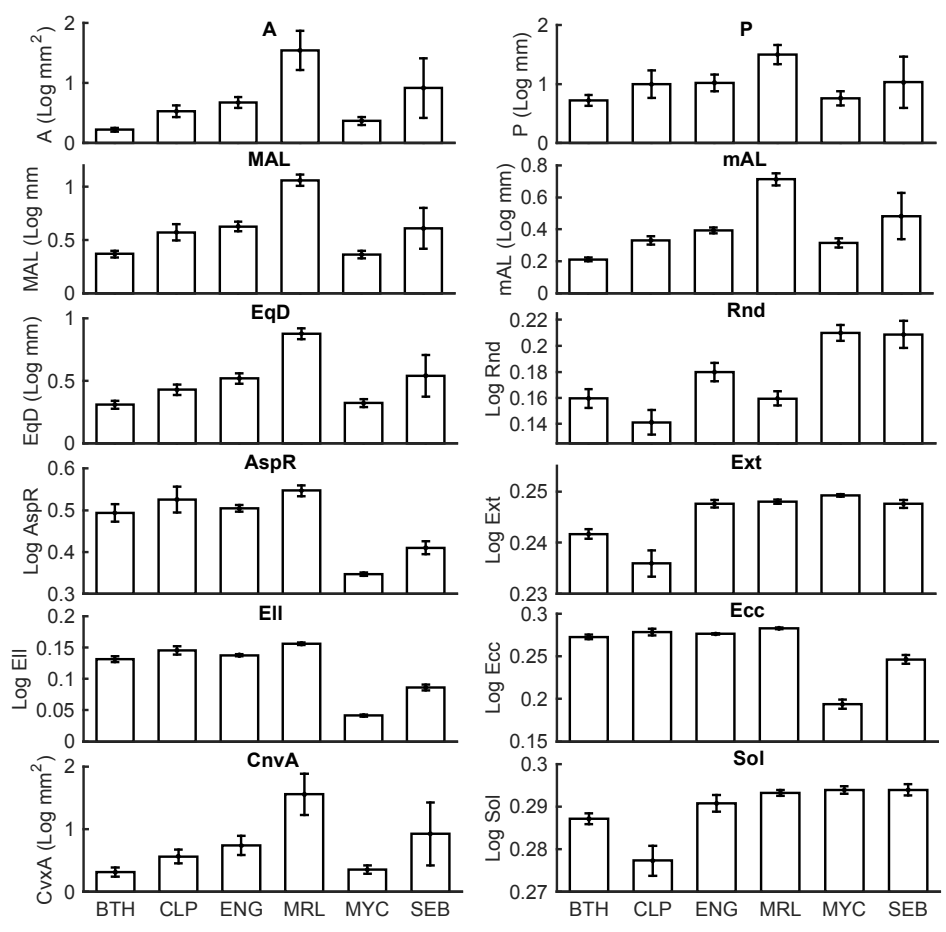

Figure 3. Mean and standard error of log-transformed geometric otolith features for different taxonomic groups of fish from the southern California Current System for ME $(\mathrm{n}=143)$. BTH = Bathylagidae $(\mathrm{n}=31)$, CLP $=$ Clupeidae $(\mathrm{n}=18), \mathrm{ENG}=$ Engraulidae $(\mathrm{n}=11), M R L=$ Merlucciidae $(\mathrm{n}=9), \mathrm{MYC}=$ Myctophidae $(\mathrm{n}=59)$, SEB $=$ Sebastidae $(n=15)$. Feature abbreviations can be found in Table S2. 
Otolith Classification

Figure 4
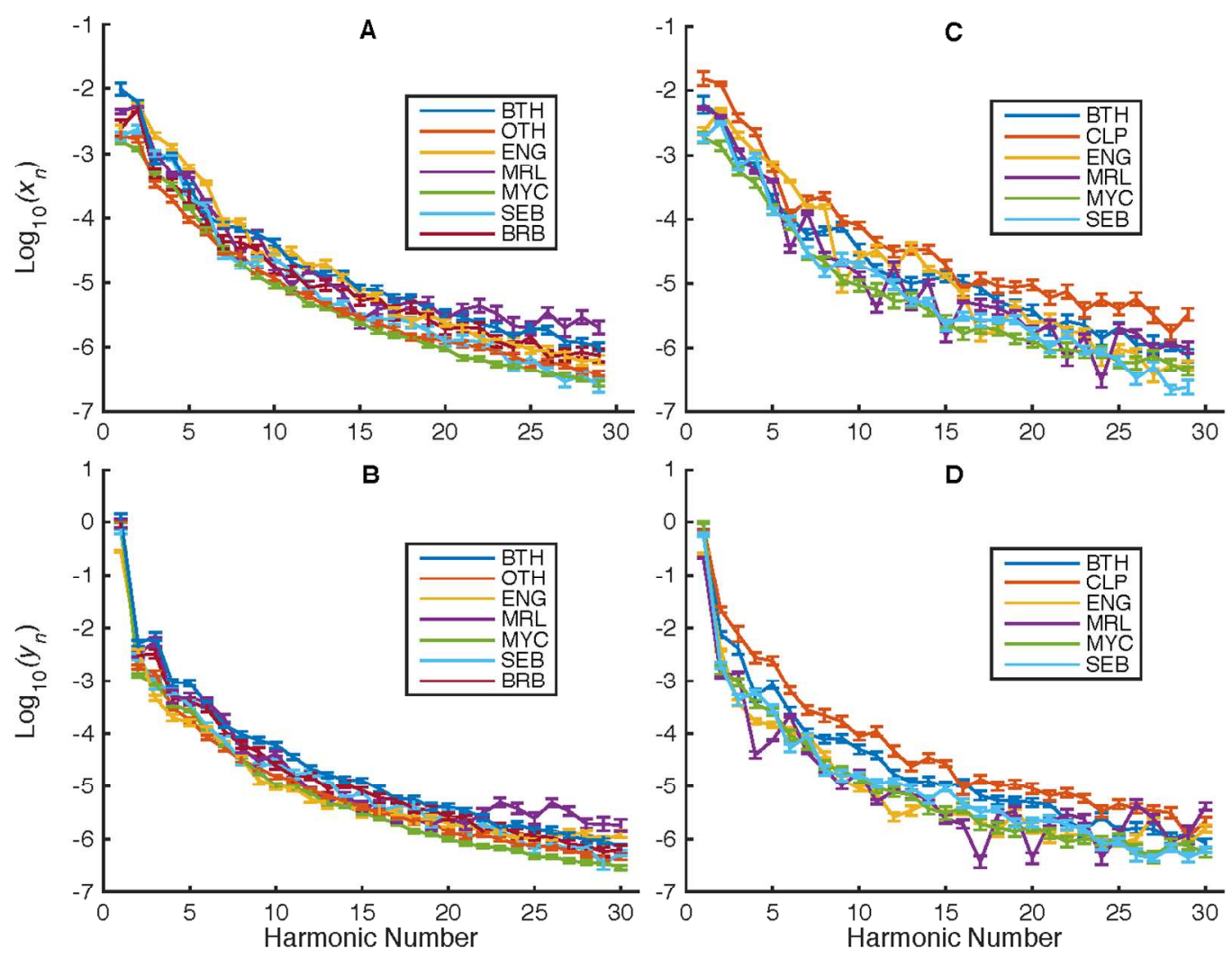

Figure 4. $\log _{10}$ of elliptic Fourier descriptors $x$ and $y$ for $M(A, B)$ and ME (C, D) in relation to harmonic number. Mean with standard error bars shown. Abbreviations for taxonomic groups as in Figs. 2 and 3. 
Otolith Classification

Figure 5

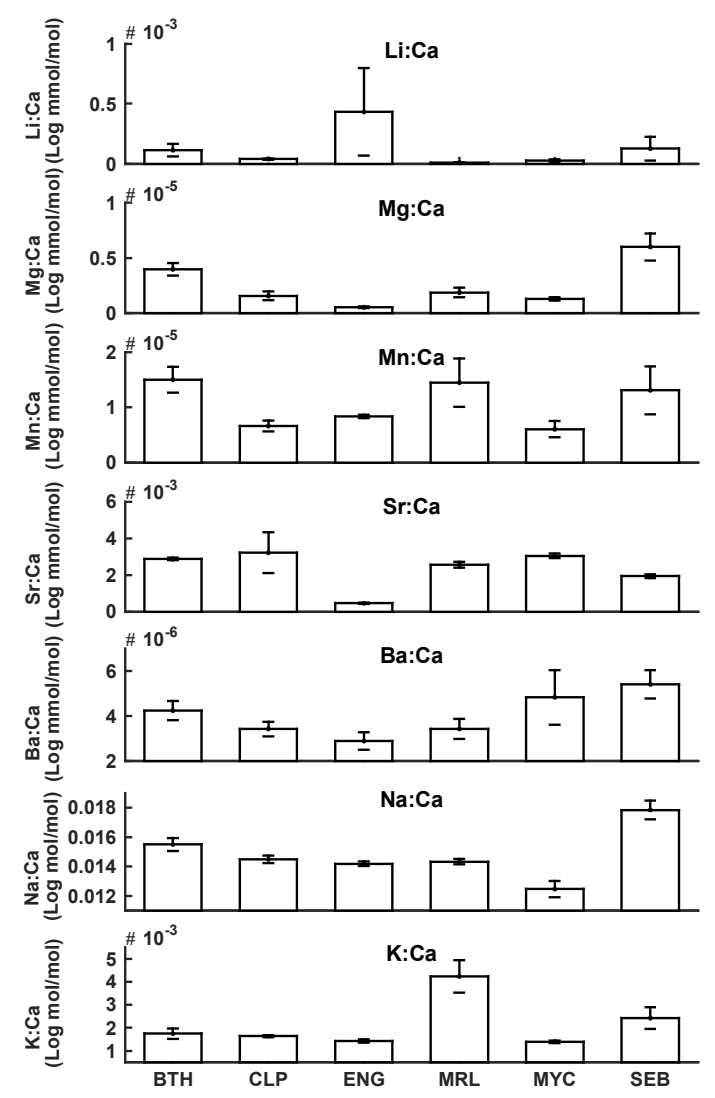

Figure 5. Mean and standard error element concentrations of six

taxonomic groups for ME $(n=143)$. Taxonomic group abbreviations as in Fig. 3. 


\section{Otolith Classification}

Figure 6
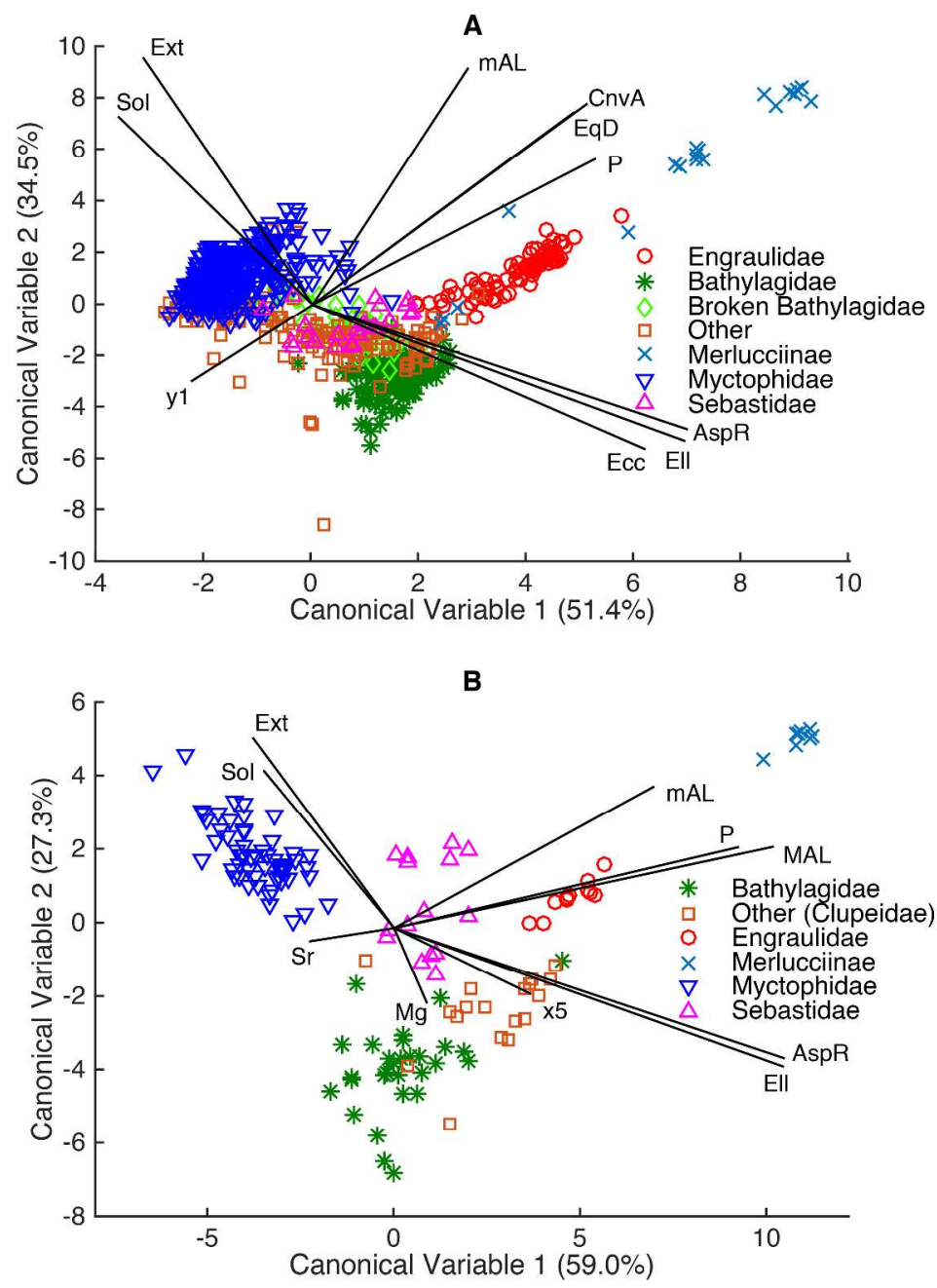

Figure 6. Canonical function analysis of otolith features for the two best classification models. Symbols represent individual otoliths. Vectors represent relative importance of features in explaining canonical function variability. A) M (morphology only) otoliths from seven taxonomic groups using ten features in the RFA10 Rank model. Canonical Variables 1 and 2 explain 51.4\% and 34.5\%, respectively, of variability in M otoliths. B) ME (morphology and element concentration) otoliths from six taxonomic groups using 10 features included in the DFA10 SW model. Canonical Variables 1 and 2 explained $59.0 \%$ and $27.3 \%$, respectively, of the variability in the ME otoliths. Feature abbreviations as in text and Table S3. 
Otolith Classification 
Otolith Classification

Table 1. M otoliths $(\mathrm{n}=905)$ analyzed for geometric (GF) and elliptic Fourier (EF) features.

Collection and feature data are in Table S1.

\begin{tabular}{l|cc}
\hline $\begin{array}{l}\text { Taxonomic } \\
\text { Group }\end{array}$ & $\begin{array}{l}\text { Number of } \\
\text { Species in } \\
\text { Group }\end{array}$ & $\begin{array}{c}\text { Number of } \\
\text { Otoliths }\end{array}$ \\
\hline Engraulidae & 1 & 82 \\
\hline Bathylagidae & 3 & 130 \\
\hline Broken & 1 & 51 \\
Bathylagidae & 1 & 19 \\
\hline Merlucciidae & 15 & 368 \\
\hline Myctophidae & 4 & 24 \\
\hline Sebastidae & 21 & 231 \\
\hline Other & & \\
\hline
\end{tabular}




\section{Otolith Classification}

Table 2. ME otoliths $(n=143)$ analyzed for geometric (GEO), elliptic Fourier (EF), and element (ELM) concentration features. Collection and feature data are in Table S2.

\begin{tabular}{l|lr}
\hline \multicolumn{1}{l}{ Taxonomic } & Species & $\begin{array}{r}\text { Number of } \\
\text { Otoliths }\end{array}$ \\
\hline Group & Leuroglossus stilbius & 11 \\
& Lipolagus ochotensis & 5 \\
& Bathylagus wesethi & 15 \\
\hline Clupeidae & Sardinops sagax & 18 \\
\hline Engraulidae & Engraulis mordax & 11 \\
\hline Merlucciidae & Merluccius productus & 6 \\
\hline Myctophidae & Triphoturus mexicanus & 6 \\
& Tarletonbeania crenularis & 16 \\
& Stenobrachius leucopsarus & 4 \\
& Protomyctophum crockeri & 11 \\
& Diaphus theta & 16 \\
\hline Sebastidae & Nannobrachium ritteri & 15 \\
\hline
\end{tabular}


Otolith Classification

Table 3. ANOVA summary for otolith features in M (morphology) and ME (morphology

908 and elemental composition). Each element in the table body contains the number of tests in which the null hypothesis was rejected (numerator) and accepted (denominator). One-

910 way ANOVA (parametric) and Kruskal-Wallis ANOVA (non-parametric) tested the null hypothesis of no difference between means of a feature among taxonomic groups (seven

912 for M, six for ME). Multi-factor ANOVA (parametric) tested the null hypothesis of no difference between means of a feature among taxonomic groups, fish size (five ranges)

914 and collection location (three regions) and year (four periods). $N_{\text {feature }}$ is the number of features in a feature type and hence the number of tests. Test results are in Tables S4 (M)

916 and S5 (ME).

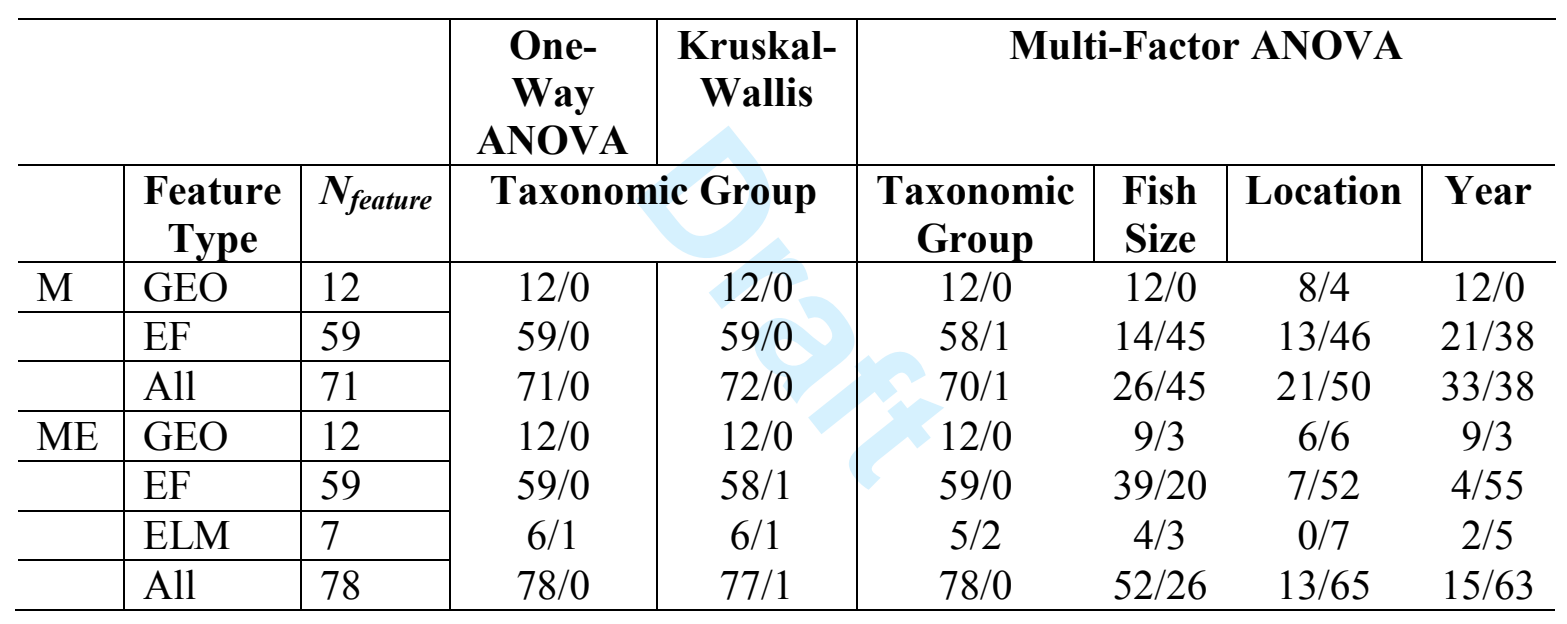


Otolith Classification

Table 4. Classification model results using both discriminant function analysis (DFA) and a random forest analysis (RFA) evaluated using a 10-fold cross-validation procedure carried out 100 times.

\begin{tabular}{|c|c|c|c|c|c|c|c|}
\hline Feature Set & Group & $\begin{array}{c}\text { Number } \\
\text { of } \\
\text { otoliths }\end{array}$ & $\begin{array}{l}\text { Number } \\
\text { of } \\
\text { features }\end{array}$ & $\begin{array}{c}\text { Mean } \\
\text { cross- } \\
\text { val. } \\
\text { error } \\
\text { (DFA) }\end{array}$ & $\begin{array}{c}\text { Stdev. } \\
\text { cross- } \\
\text { val. } \\
\text { error } \\
\text { (DFA) }\end{array}$ & $\begin{array}{c}\text { Mean } \\
\text { cross- } \\
\text { val } \\
\text { error } \\
\text { (RFA) }\end{array}$ & $\begin{array}{c}\text { Stdev. } \\
\text { cross- } \\
\text { val } \\
\text { error } \\
\text { (RFA) }\end{array}$ \\
\hline GEO & $\mathrm{M}$ & 905 & 12 & 0.221 & 0.003 & 0.146 & 0.005 \\
\hline $\mathrm{EF}$ & M & 905 & 59 & 0.407 & 0.008 & 0.250 & 0.007 \\
\hline GEO, EF & M & 905 & 71 & 0.190 & 0.005 & 0.141 & 0.002 \\
\hline DFA10 SW M* & M & 905 & 10 & 0.220 & 0.003 & 0.125 & 0.001 \\
\hline RFA10 Rank* & M & 905 & 10 & 0.250 & 0.003 & 0.118 & 0.004 \\
\hline GEO & $\mathrm{ME}$ & 143 & 12 & 0.066 & 0.012 & 0.080 & 0.008 \\
\hline $\mathrm{EF}$ & $\mathrm{ME}$ & 143 & 59 & 0.343 & 0.024 & 0.132 & 0.016 \\
\hline ELM & $\mathrm{ME}$ & 143 & 6 & 0.491 & 0.008 & 0.171 & 0.015 \\
\hline GEO, ELM & $\mathrm{ME}$ & 143 & 18 & 0.071 & 0.008 & 0.050 & 0.017 \\
\hline $\mathrm{GEO}, \mathrm{EF}$ & $\mathrm{ME}$ & 143 & 71 & 0.102 & 0.012 & 0.073 & 0.011 \\
\hline GEO, EF, ELM & $\mathrm{ME}$ & 143 & 77 & 0.108 & 0.015 & 0.046 & 0.008 \\
\hline DFA10 SW ME* & $\mathrm{ME}$ & 143 & 10 & 0.037 & 0.004 & 0.049 & 0.005 \\
\hline RFA10 Rank* & $\mathrm{ME}$ & 143 & 10 & 0.110 & 0.011 & 0.056 & 0.019 \\
\hline
\end{tabular}

*Refer to Table 4 for list features included in these models. GEO = Geometric Features, EF = Elliptic Fourier $x$ and $y$ components, ELM = Element concentration features.

920

922 


\section{Otolith Classification}

Table 5. Features included in the ten-feature DFA SW and RFA rank models for M and ME.

\begin{tabular}{l|clllc}
\hline Model & Group & GEO* & EF* & ELM* \\
\hline DFA SW & $\mathrm{M}$ & $E q D, A s p R, P, S o l, C n v A, E x t, A$ & $x 3, y 3, y 2$ & N/A \\
\hline RFA10 rank & $\mathrm{M} \quad \begin{array}{l}E x t, E q D, C n v A, m A L, E c c, A s p R, E l l, \\
\text { Sol, } P\end{array}$ & $y l$ & N/A \\
& & AspR, Ext, Sol, MAL, P, $m A L, E l l$ & $x 5$ & $\mathrm{Sr}, \mathrm{Mg}$ \\
\hline DFA10 SW & $\mathrm{ME}$ & $\begin{array}{l}E c c, A s p R, E l l, E x t, m A L, A, S o l, M A L, \\
\text { RFA rank }\end{array}$ & $\mathrm{ME}$ & - & $\mathrm{Sr}$ \\
& & $P$ & & \\
\hline
\end{tabular}

*Refer to text and Table S3 for feature abbreviations and descriptions. 
Table S7. Tukey HSD test results for ME. Mean and standard error (SE) are displayed. EL: DFA10 SW = ME reduced model.

\section{ME Taxa}

Bathylagidae

Clupeidae (Other)

Engraulidae

Merlucciidae

Myctophidae

Sebastidae
Number of otoliths

3121.67832168

$18 \quad 12.58741259$

117.692307692

$9 \quad 6.293706294$

$59 \quad 41.25874126$

$15 \quad 10.48951049$
ELM mean ELM SE

$0.00076 \quad 0.00008$

$0.00071 \quad 0.00011$

$0.00062 \quad 0.00013$

$0.00184 \quad 0.00015$

$0.00060 \quad 0.00006$

$0.00105 \quad 0.00012$ 
$\mathrm{M}=$ Elemental features, GEO = Geometric features, EF = Elliptic Fourier Features, ALL = all feature

\section{GEO mean GEO SE EF mean EF SD ALL mean ALL SE DFA10 SW Mean}

$\begin{array}{lllllll}0.287 & 0.0007 & 0.0000008 & 3.3 \mathrm{E}-07 & -6.06 & 0.106 & -3.20\end{array}$

$\begin{array}{lllllll}0.277 & 0.0010 & 0.0000025 & 4.4 \mathrm{E}-07 & -5.67 & 0.140 & -2.64\end{array}$

$\begin{array}{lllllll}0.291 & 0.0012 & 0.0000011 & 5.6 \mathrm{E}-07 & -5.80 & 0.179 & -2.95\end{array}$

$\begin{array}{lllllll}0.293 & 0.0014 & 0.0000030 & 6.2 \mathrm{E}-07 & -5.39 & 0.198 & -3.27\end{array}$

$\begin{array}{lllllll}0.294 & 0.0005 & 0.0000006 & 2.4 \mathrm{E}-07 & -6.25 & 0.077 & -3.44\end{array}$

$\begin{array}{lllllll}0.294 & 0.0011 & 0.0000004 & 4.8 \mathrm{E}-07 & -6.19 & 0.153 & -3.00\end{array}$ 
s included,

\section{DFA10 SW SE}

0.09

0.12

0.15

0.16

0.06

0.13 


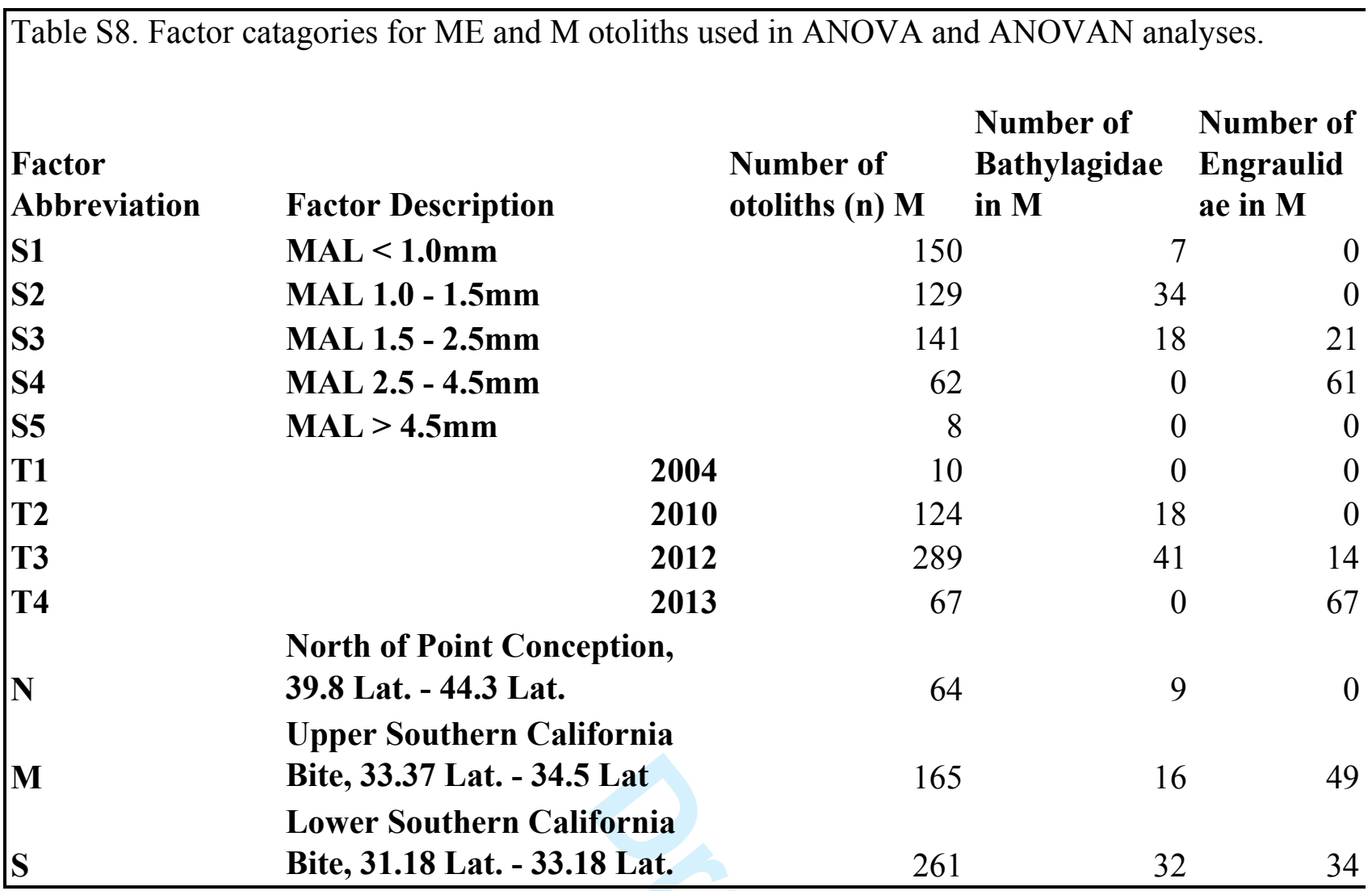




\begin{tabular}{|c|c|c|c|c|c|c|}
\hline $\begin{array}{l}\text { Number of } \\
\text { Merlucciid } \\
\text { ae in } M\end{array}$ & $\begin{array}{l}\text { Number of } \\
\text { Myctophidae in } \\
\text { M }\end{array}$ & $\begin{array}{l}\text { Number of } \\
\text { Sebastidae } \\
\text { in } M\end{array}$ & $\begin{array}{l}\text { Number of } \\
\text { Broken } \\
\text { Bathylagidae } \\
\text { in } M\end{array}$ & $\begin{array}{l}\text { Number of } \\
\text { Other in } \mathbf{M}\end{array}$ & $\begin{array}{l}\text { Number of } \\
\text { otoliths (n) } \\
\text { ME2 }\end{array}$ & $\begin{array}{l}\text { Number of } \\
\text { Bathylagida } \\
\text { e in ME3 }\end{array}$ \\
\hline 0 & 103 & 6 & & 32 & 32 & 4 \\
\hline 0 & 67 & 8 & & 15 & 38 & 21 \\
\hline 0 & 78 & 9 & & 16 & 32 & 5 \\
\hline 0 & 0 & 1 & & 0 & 26 & 1 \\
\hline 7 & 0 & 0 & & 0 & 15 & 0 \\
\hline 0 & 0 & 0 & & 10 & 6 & 0 \\
\hline 0 & 51 & 0 & & 25 & 13 & 0 \\
\hline 0 & 197 & 24 & & 28 & 113 & 31 \\
\hline 7 & 0 & 0 & & 0 & 11 & 0 \\
\hline 1 & 54 & 0 & & 10 & 18 & 6 \\
\hline 0 & 74 & 20 & & 0 & 68 & 15 \\
\hline 6 & 120 & 4 & 8 & 57 & 37 & 10 \\
\hline
\end{tabular}




\begin{tabular}{|c|c|c|c|c|c|}
\hline $\begin{array}{l}\text { Number of } \\
\text { Clupidae in ME4 }\end{array}$ & $\begin{array}{l}\text { Number of } \\
\text { Engraulida } \\
\text { e in ME5 }\end{array}$ & $\begin{array}{l}\text { Number of } \\
\text { Merlucciida } \\
\text { e in ME6 }\end{array}$ & $\begin{array}{l}\text { Number of } \\
\text { Myctophidae in } \\
\text { ME7 }\end{array}$ & & $\begin{array}{l}\text { Number of } \\
\text { Sebastidae } \\
\text { in ME8 }\end{array}$ \\
\hline 0 & 0 & 0 & & 27 & 1 \\
\hline 0 & 0 & 0 & & 11 & 6 \\
\hline 7 & 1 & 0 & & 17 & 2 \\
\hline 11 & 10 & 0 & & 4 & 0 \\
\hline 0 & 0 & 9 & & 0 & 6 \\
\hline 6 & 0 & 0 & & 0 & 0 \\
\hline 0 & 0 & 0 & & 4 & 9 \\
\hline 12 & 0 & 9 & & 55 & 6 \\
\hline 0 & 11 & 0 & & 0 & 0 \\
\hline 6 & 0 & 0 & & 6 & 0 \\
\hline 0 & 6 & 0 & & 123 & 9 \\
\hline 12 & 5 & 9 & & 15 & 6 \\
\hline
\end{tabular}


Table S9. Percent of total occurance of ichthyoplankton (larvae only) from 1951 to 2011 during Califi Oceanic Fisheries Investigations (CalCOFI) cruises. The 20 most common taxa are displayed. CalCO entire CalCOFI sampling region; SBB Region represents line 80 - stations 51-5, lines 80.8-82.7 - stati 83.3 - stations 40.6-55; SBB Station represents lines 81.5-82 - stations 46-47. Taxa catagory represe taxonomic catagories used in this study.

\begin{tabular}{|l|l|l|r|r|}
\hline Species & Family & Taxa category & CalCOFI & SBB Region \\
\hline Engraulis mordax & Engraulidae & Engraulidae & 48.92 & 47.33 \\
\hline Merluccius productus & Merlucciidae & Merlucciidae & 13.77 & 18.36 \\
\hline Leuroglossus stilbius & Bathylagidae & Bathylagidae & 5.95 & 6.67 \\
\hline Sebastes & Sebastidae & Sebastidae & 5.46 & 10.35 \\
\hline Vinciguerria lucetia & Phosichthyidae & Other & 4.7 & 0.022 \\
\hline Stenobrachius leucopsarus & Myctophidae & Myctophidae & 4.06 & 4.42 \\
\hline Sardinops sagax & Clupeidae & Clupeidae (Other) & 3.48 & 2.49 \\
\hline Trachurus symmetricus & Carangidae & - & 1.39 & 0.05 \\
\hline Sebastes jordani & Sebastidae & Sebastidae & 1.18 & 2.83 \\
\hline Lipolagus ochotensis & Bathylagidae & Bathylagidae & 0.97 & 0.44 \\
\hline Triphoturus mexicanus & Myctophidae & Myctophidae & 0.71 & 0.13 \\
\hline Bathylagoides wesethi & Bathylagidae & Bathylagidae & 0.69 & 0.01 \\
\hline Protomyctophum crockeri & Myctophidae & Myctophidae & 0.62 & 0.12 \\
\hline Ceratoscopelus townsendi & Myctophidae & Myctophidae & 0.56 & 0 \\
\hline Citharichthys stigmaeus & Paralichthyidae & - & 0.51 & 0.8 \\
\hline Genyonemus lineatus & Sciaenidae & - & 0.43 & 1.08 \\
\hline Nannobrachium ritteri & Myctophidae & Myctophidae & 0.4 & 0.05 \\
\hline Diogenichthys atlanticus & Myctophidae & Myctophidae & 0.39 & 0.02 \\
\hline Symbolophorus californiensis & Myctophidae & Myctophidae & 0.37 & 0.01 \\
\hline Tarletonbeania crenularis & Myctophidae & Myctophidae & 0.36 & 0.17 \\
\hline
\end{tabular}


srnia Cooperative IFI represents the ions 43.5-54, line nts the

\section{SBB Station}

50.67

4.82

11.99

10.17

0.02

5.34

3.96

0.07

2.75

0.19

0.18

0.01

0.06

1.54

0.84

0.04

0.03

0.06 


\section{SUPPLEMENTARY FIGURES AND TABLES}

2

Figure S1

4

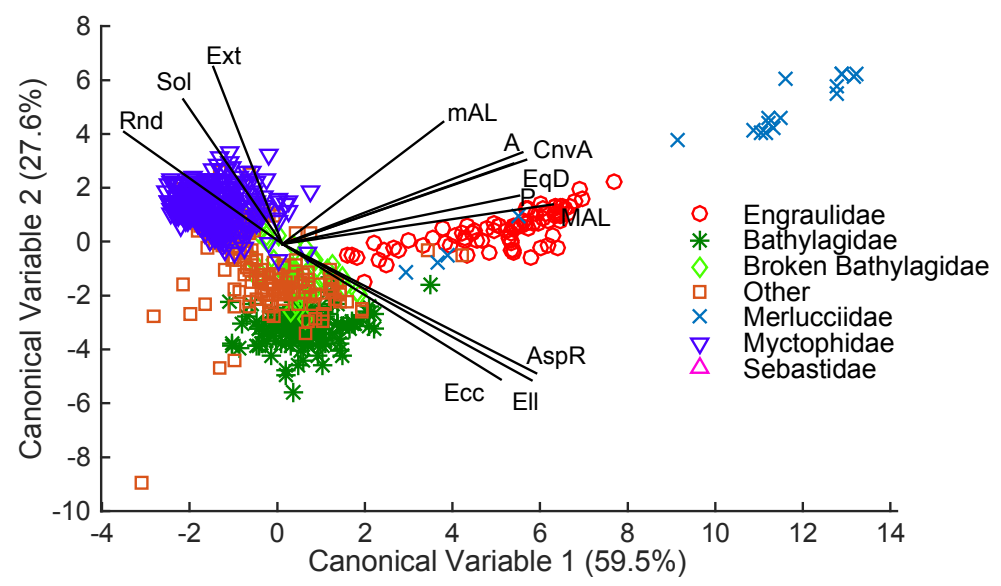

6

Figure S1. Canonical function analysis using GEO features for M otoliths. Symbols

8 represent individual otoliths $(\mathrm{n}=905)$. Vectors represent relative importance of features in explaining canonical function variability. Canonical Variables 1 and 2 explained

$1059.5 \%$ and $27.6 \%$, respectively, of otolith features. Feature abbreviations in Table S3. 


\section{Otolith Classification}

\section{$14 \quad$ Figure $\mathrm{S} 2$}

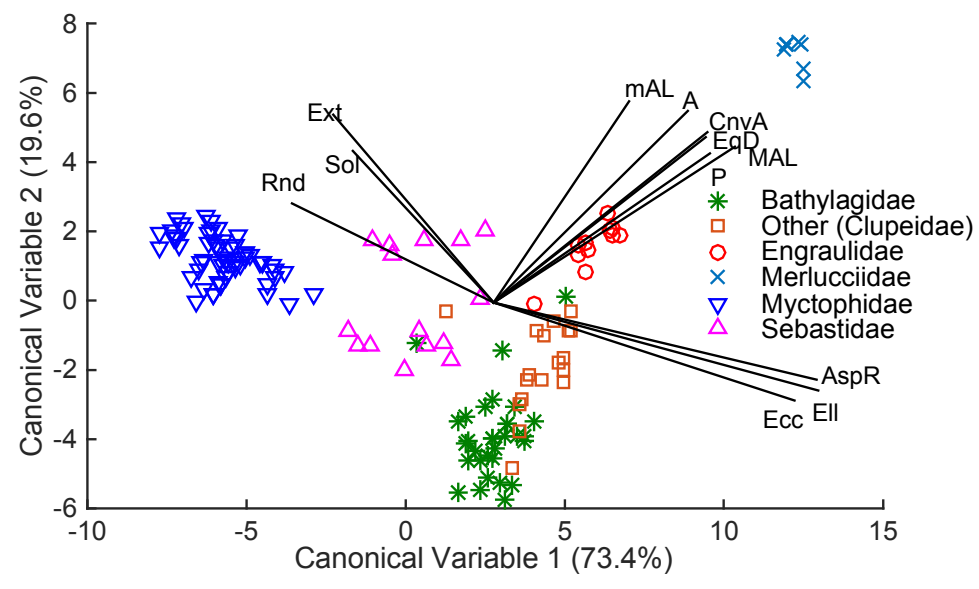

18 Figure S2. Canonical function analysis using GEO features for ME otoliths. Symbols represent individual otoliths $(n=143)$. Vectors represent relative importance of features

20 in explaining canonical function variability. Canonical Variables 1 and 2 explained $73.4 \%$ and $19.6 \%$, respectively, of otolith features. Feature abbreviations in Table S3.

22 


\section{Otolith Classification}

\section{Figure S3}

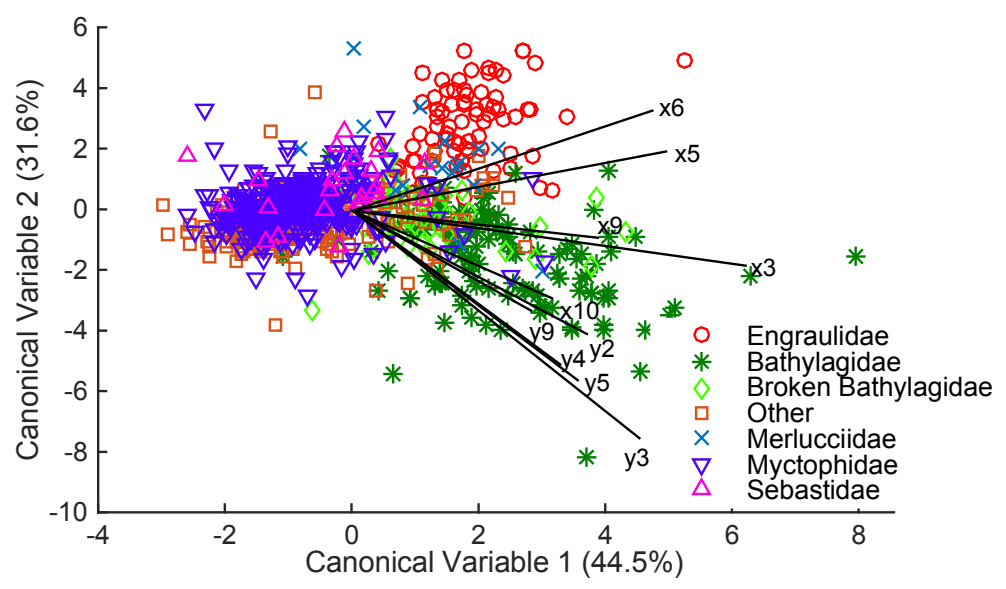

28

30 Figure S3. Canonical function analysis using EF features for M otoliths. Symbols represent individual otoliths $(n=905)$. Vectors represent relative importance of features

32 in explaining canonical function variability. Only the ten strongest discriminatory features are displayed as vectors. Canonical Variables 1 and 2 explained $44.5 \%$ and

$3431.6 \%$, respectively, of otolith features. Feature abbreviations in Table S3. 


\section{Otolith Classification}

\section{$38 \quad$ Figure S4}

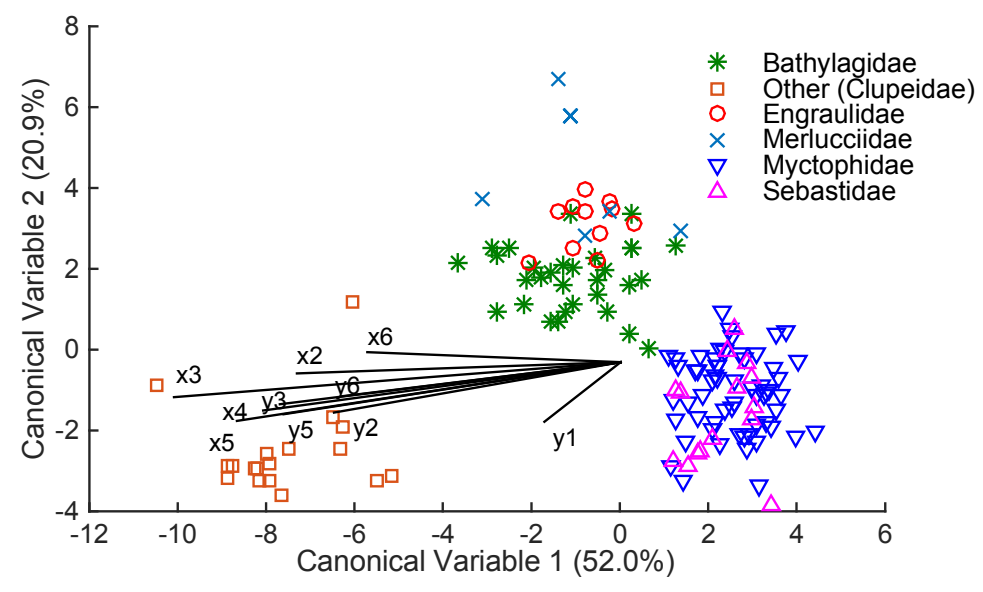

42 Figure S4. Canonical function analysis using EF features for ME otoliths. Symbols represent individual otoliths $(n=143)$. Vectors represent relative importance of features

44 in explaining canonical function variability. Only the ten strongest discriminatory features are displayed as vectors. Canonical Variables 1 and 2 explained 52.0\% and $4620.9 \%$, respectively, of otolith features. Feature abbreviations in Table S3. 


\section{Otolith Classification}

$50 \quad$ Figure S5

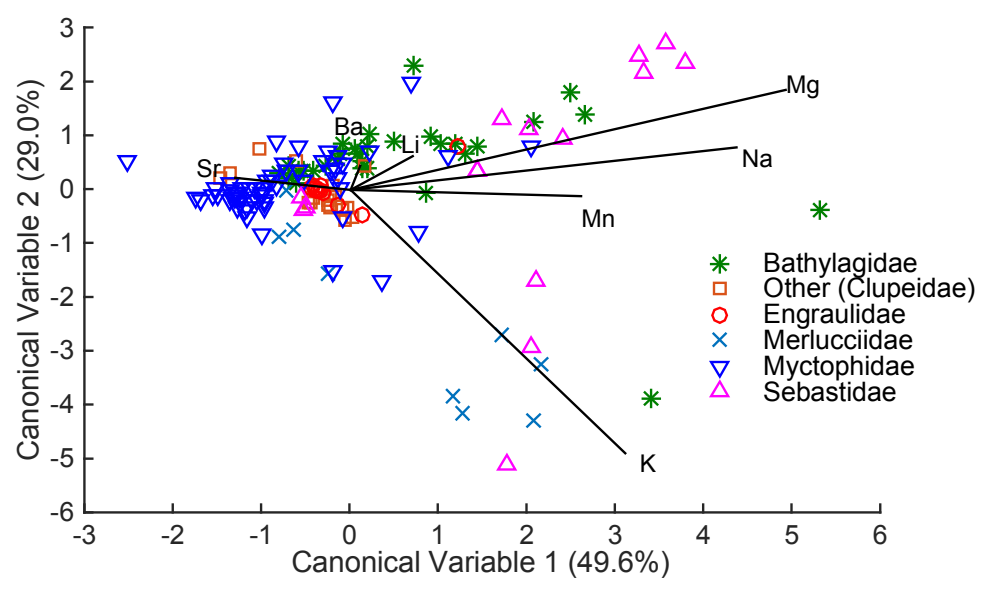

54 Figure S5. Canonical function analysis using ELM features for ME otoliths. Symbols represent individual otoliths $(n=143)$. Vectors represent relative importance of features

56 in explaining canonical function variability. Canonical Variables 1 and 2 explained $49.6 \%$ and $29.0 \%$, respectively, of otolith features. Feature abbreviations in Table S3.

58

60 
Otolith Classification

Tables S1-S9 are in SI Excel file.

62

Table S10. ANOVA summary for otolith features in M (morphology) and ME

64 (morphology and elemental composition). Each element in the table body contains the number of tests in which the null hypothesis was rejected (numerator) and accepted

66 (denominator). One-Way ANOVA (parametric) and Kruskal-Wallis ANOVA (nonparametric) tested the null hypothesis of no difference between means of a feature among

68 taxonomic groups (seven for M, six for ME). Multi-factor ANOVA (parametric) tested the null hypothesis of no difference between means of a feature among taxonomic

70 groups, fish size (five ranges) and collection location (three regions) and year (four periods). $N_{\text {feature }}$ is the number of features in a feature type and hence the number of tests.

72 Bonferroni correction for multiple comparisons was made for $\mathrm{M}\left(\alpha_{\text {corrected }}=0.05 / 426\right)$ and $\operatorname{ME}\left(\alpha_{\text {corrected }}=0.05 / 468\right)$. Test results are in Tables S4 (M) and S5 (ME).

74

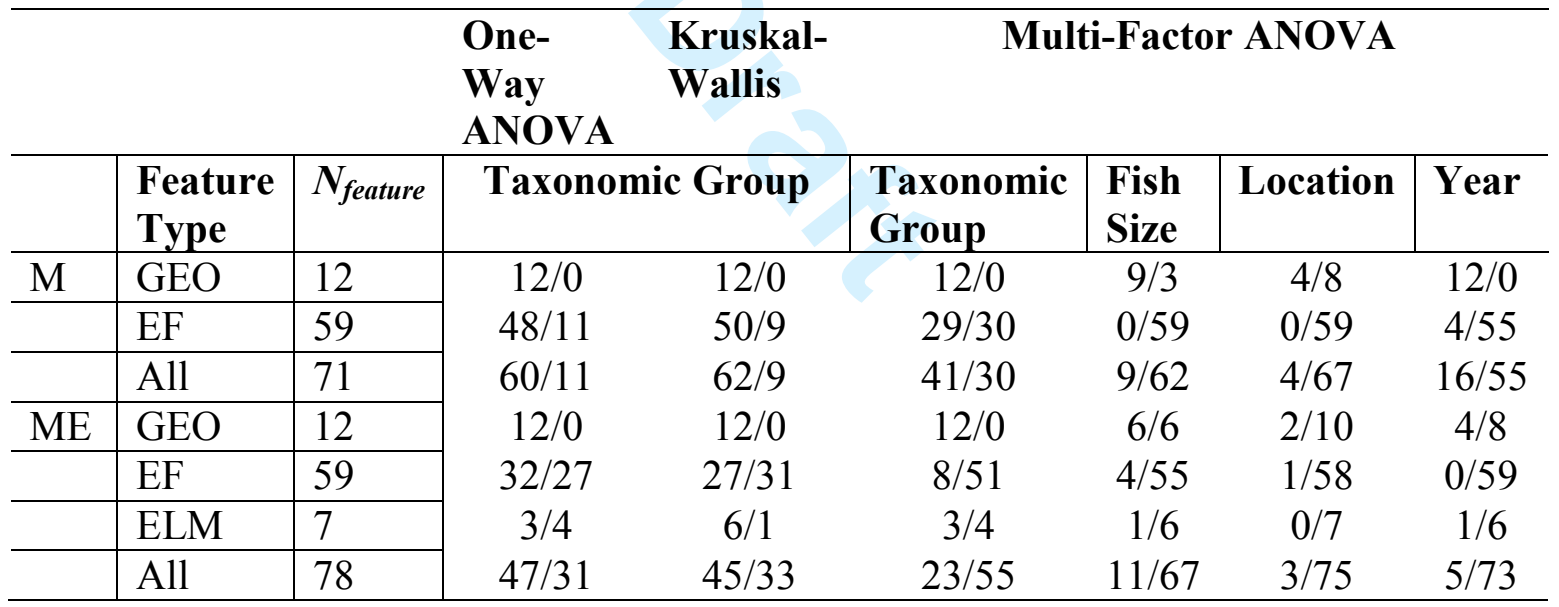

